\title{
Probing the Interior of Self-Assembled Caffeine Dimer at Various Temperatures
}

\section{Soma Banerjee, Pramod Kumar Verma, Rajib Kumar Mitra, Gautam Basu \& Samir Kumar Pal}

\section{Journal of Fluorescence}

ISSN 1053-0509

Volume 22

Number 2

J Fluoresc (2012) 22:753-769

DOI 10.1007/s10895-011-1011-3

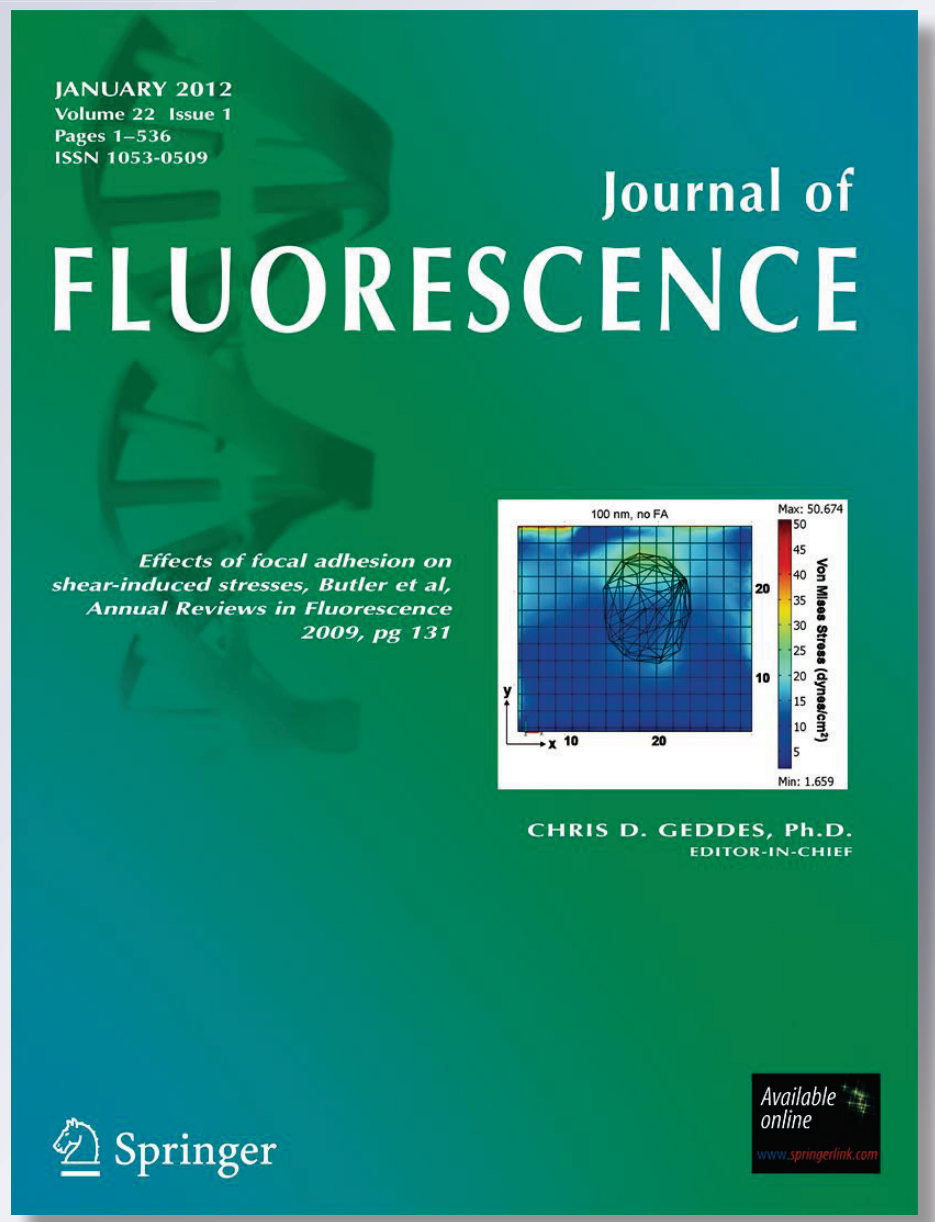

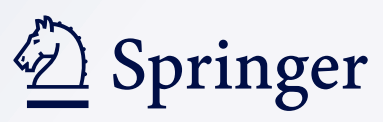




\title{
Probing the Interior of Self-Assembled Caffeine Dimer at Various Temperatures
}

\author{
Soma Banerjee • Pramod Kumar Verma • \\ Rajib Kumar Mitra • Gautam Basu • Samir Kumar Pal
}

Received: 12 July 2011 /Accepted: 20 October 2011 /Published online: 10 November 2011

(C) Springer Science+Business Media, LLC 2011

\begin{abstract}
The self-assembly of non-toxic well-consumed small caffeine molecules into well-defined structures has important implications for future medical applications seeking to target the transport of small drugs in human body. Particularly, the solvation of the microenvironments of the self assembly ultimately dictates the interaction with the drug molecules and their therapeutic efficacy. We present femtosecond-resolved studies of the dynamics of aqueous solvation within self-assembled dimeric structure of caffeine molecules. We have placed small hydrophobic probes 4-(dicyanomethylene)-2-methyl-6-(p-dimethylaminostyryl) 4H-pyran (DCM), coumarin 500 (C500) into the caffeine dimer to enable spectroscopic examinations of the interior. While molecular modeling and NMR studies of the probes in the caffeine dimers reveal a well-defined location (stacked in between two caffeine molecules), dynamical light scattering (DLS), Fourier transform infrared (FTIR) spectroscopy, densimetric and sonometric experiments
\end{abstract}

Electronic supplementary material The online version of this article (doi:10.1007/s10895-011-1011-3) contains supplementary material, which is available to authorized users.

S. Banerjee $\cdot$ P. K. Verma $・$ R. K. Mitra $\cdot$ S. K. Pal $(\bowtie)$

Unit for Nano Science \& Technology, Department of Chemical,

Biological \& Macromolecular Sciences, S. N. Bose National

Centre for Basic Sciences,

Block JD, Sector III,

Salt Lake, Kolkata 700 098, India

e-mail: skpal@bose.res.in

G. Basu

Department of Biophysics, BOSE INSTITUTE,

P 1/12, C. I. T. Road, Scheme - VIIM,

Kolkata 700054, West Bengal, India explore the structural evolution of the dimer upon complexation with the probes. We have extended our studies in various temperatures in order to explore structural evolution of the self assembled structure and consequently the dynamics of solvation in the interior of the dimer. Picoseconds/femtosecond resolved dynamics and the polarization gated spectroscopic studies unravel the hydration and energetics associated with activated viscous flow of the confined probes. Our studies indicate that the interior of the caffeine dimer is well-solvated; however, the dynamics of solvation is retarted significantly compared to that in bulk water, clearly revealing the dimers maintain some ordered water molecules. We have also explored the consequence of the retarded dynamics of solvation on the photo-induced electron transfer (ET) reaction of a model probe, 2-(ptoluidino) naphthalene-6-sulfonate (TNS) encapsulated in the dimer.

Keywords Femtosecond-resolved hydration dynamics . Caffeine dimer interior . NMR spectroscopy of caffeineTNS hetero association - TICT in caffeine dimer - Activation energy for the viscous flow

\section{Introduction}

Caffeine (1,3,7-trimethylxanthine) is in a class of molecules with conjugated planer ring systems that constitute the most widely distributed naturally occurring methylxanthines and regularly consumed by human beings from various dietary sources (e.g. coffee, tea, cola beverages, chocolates). Relatively higher consumption of the molecule due to 
abundance of methylxanthines (mainly caffeine) in human diets, has directed extensive research on the activity of the molecule in the cellular environments in the recent past [1, 2]. It is clearly demonstrated that caffeine has multiplicity of effects on cells. Particularly, it has been shown in a number of earlier studies that caffeine has variety of roles on the molecular recognition of DNA by intercalating drugs $[2,3]$. For example, when combined with a wide range of DNA-damaging agents (e.g. mitomycin C, cytophosphamide, cisplatinum, hydroxyl urea), caffeine enhances cell killing [4-6]. On the other hand another set of studies have indicated that caffeine can diminish the cytotoxic/cytostatic effects of doxorubicin, ethidium bromide [7-10] and reverses cytotoxic effect of the antitumor agent mitoxantrone, eilipticine and doxorubicin analogues [11]. The rational answer of the obvious question from the earlier studies that why does caffeine potentiate toxic effects in one group of drugs while having opposite effect on others, would be the specific molecular interaction of caffeine with individual drug molecule underlying in the "interceptor" action of caffeine $[2,3]$. For the physiological activity of the drugs in presence of caffeine another mechanism of action called "protector", has been proposed, in which there is competition between caffeine and another aromatic drug for the binding sites on DNA [3, 11]. The activity of the molecule as mood altering substance is within the central nervous system where it acts as stimulant, perhaps by competitive blockage of endogenous adenosine at $A_{1}$ and $\mathrm{A}_{2 \mathrm{~A}}$ receptors [12].

From the brief survey of the earlier studies it is clear that caffeine can be used to host small ligands (drugs) and deliver/remove the same in a specific site of adenosine receptor or DNA. In other words the molecular basis of use of the well known molecules as drug delivery/recovery system needs some attention. It is well known that specific interaction of a molecule/macromolecule with each other in aqueous solutions heavily depends on hydration of the molecule/macromolecules [13]. In this regard caffeine should be considered as an interesting system because of the simultaneous presence of $-\mathrm{CH}_{3}$ and $-\mathrm{OH}$ groups on its structure (Scheme 1). The structure of the molecule limits the solubility in water because of the self association of the molecule by hydrophobic interaction and it is also responsible for complexation with other drug molecules in aqueous solutions. A detail NMR followed by molecular modeling studies confer that most stable self aggregation of caffeine is its dimeric form [14, 15]. Earlier, spectroscopic and molecular modeling studies of caffeine complexes with other aromatic drugs reveal replacement of water molecules solvating the drugs by the more hydrophobic caffeine molecules [2]. The studies have also concluded that caffeine could make complex with drugs via $\pi-\pi$ type of interaction. In a recent Monte Carlo simulation study similar binding mechanism of caffeine with DNA-base pairs has been proposed [16].

It has to be noted that the most of the DNA-binding drugs reveal charge transfer (CT) reaction upon $\pi$-stacking with DNA base pairs $[17,18]$. Thus the possibility of CT reaction of any drug upon complexation with caffeine molecule would be an interest for the molecular understanding of the interaction of caffeine with the drug. It is well established that the solvent relaxation time scales influence the dynamics of charge transfer reactions by exerting a time dependent dielectric friction. In these cases the $\mathrm{CT}$ reaction rates are limited by the rate of solvent relaxation around the concerned molecule [1921]. However, till date no attempt has been made to explore the dynamics of solvent relaxation around caffeine upon complexation with other aromatic molecules. The dynamics of CT of small molecules upon complexation with caffeine also remain unexplored and are the motives of the present study.

In the present study we have explored the structure of caffeine aggregation by DLS and FTIR techniques. Temperature dependent DLS studies followed by densimetric \& sonometric measurements of the caffeine molecules in aqueous solutions explore the structural evolution of caffeine self-aggregation with temperature. These studies are of particular interest as caffeine is consumed as low and high temperature beverages. Here we have also explored the details of the complexation (solubilisation) of caffeine with a hydrophobic (completely insoluble in water) model probe 4-(dicyanomethylene)-2-methyl-6-(p-dimethylaminostyryl) 4H-pyran (DCM), a well known fluorescent reporter for the relaxation of solvent molecules, in water. Our molecular modeling on the complexation of DCM with caffeine molecules reveals that two caffeine molecules make stack geometry in order to encapsulate DCM inside the dimeric structure (Scheme 1). We have measured solvation response of water molecules around the probe DCM at $80{ }^{\circ} \mathrm{C}$ in the host caffeine dimer with limited number of water molecules and compared the time scales of the solvation with bulk water at elevated temperature. In order to establish the general nature of the solvation dynamics (independent of probe), we have used another well known solvation probe coumarin 500 (C500), where similar complexation geometry with the caffeine molecules has been modelled. Polarization gated fluorescence upconversion and time correlated single photon counting (TCSPC) have been employed to confirm the geometrical restriction of the probes under investigation. In order to investigate the consequence of the slower solvation of water molecules and restricted geometry on the photoinduced charge transfer reaction, we have studied twisted intramolecular charge transfer (TICT) of the probe 2-(ptoluidino) naphthalene-6-sulfonate (TNS) in the dimer at 
Scheme 1 The molecular structure of caffeine and the fluorescent probes DCM, C500, and TNS along with their complexes with caffeine dimer. Complexes are energy minimized structures (see text)

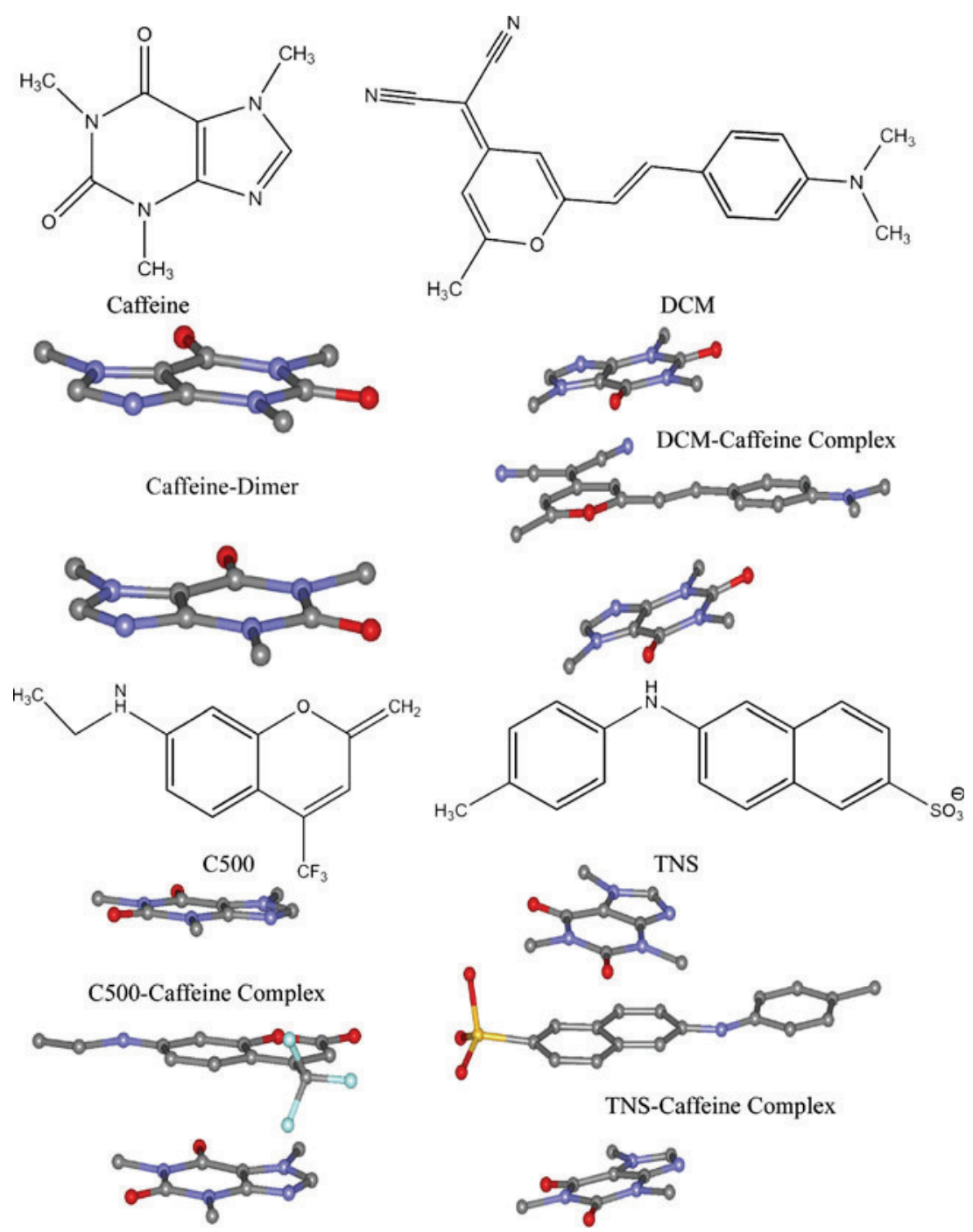

various temperatures. Our detail experimental evidences clearly establish caffeine dimer as an excellent host of small molecules, which could be useful to the further research on the application of the well consumed beverage as a potential carrier of drug for targeted delivery system.

\section{Experimental Section}

Sample Preparation

Caffeine (99.99\%) was purchased from Fluka, 4-(dicyanomethylene)-2-methyl-6-(p-dimethylaminostyryl) 4H-pyran (DCM) and coumarin 500 (C500) from Exciton and 2-(ptoluidino) naphthalene-6-sulfonate (TNS) from Sigma. All the chemicals were used without further purification. Aqueous solutions of caffeine and TNS were prepared in double distilled water. DCM and C500 were solubilized by adding them into aqueous caffeine solution followed by overnight stirring at room temperature. The whole solution was then filtered and used for spectroscopic studies. Highly concentrated caffeine solution $(0.9 \mathrm{M})$ was prepared at $80^{\circ} \mathrm{C}$ for femtosecond-resolved fluorescence study with DCM. For NMR studies the samples were prepared in phosphate buffer at $\mathrm{pH} 7.2$ using HPLC water. The concentrations of caffeine and TNS in sample solutions were determined spectrophotometrically from the absorption intensity at $\lambda=272 \mathrm{~nm}$ and $350 \mathrm{~nm}$ respectively. (molar extinction coefficient of caffeine [22] is $9900 \mathrm{M}^{-1} \mathrm{~cm}^{-1}$ at $272 \mathrm{~nm}$ while that of TNS [23] at $350 \mathrm{~nm}$ is $6640 \mathrm{M}^{-1} \mathrm{~cm}^{-1}$ ).

\section{NMR Measurements}

${ }^{1} \mathrm{H}-\mathrm{NMR}$ experiments were performed on caffeine, TNS and a mixture of the two (titrations) in aqueous phosphate buffer at $\mathrm{pH} 7.2$ (Watergate solvent suppression) using a Bruker DRX $500 \mathrm{MHz}$ spectrometer. ${ }^{1} \mathrm{H}$-signals were assigned either by comparing with literature [24] or by 
performing TOCSY and NOESY/ROESY experiments using standard protocols.

\section{Steady State Measurements}

Steady-state absorption, emission and Fourier transform infrared spectra (FTIR) were measured with Shimadzu Model UV-2450 spectrophotometer, Jobin Yvon Model Fluoromax-3 fluorimeter and JASCO FT/IR-6300 spectrometer (transmission mode) respectively. Dynamic light scattering (DLS) measurements were done with Nano $\mathrm{S}$ Malvern instruments employing a $4 \mathrm{~mW} \mathrm{He}-\mathrm{Ne}$ laser $(\lambda=$ $632.8 \mathrm{~nm}$ ) equipped with a thermostatted sample chamber. The density and ultrasonic velocitimetric studies were done with a DSA 5000 instrument from Anton Paar, with the measurement accuracy of density and sound velocity of $5 \times$ $10^{-6} \mathrm{~g} \mathrm{~cm}^{-3}$ and $0.5 \mathrm{~ms}^{-1}$, respectively. The details of DLS and densimetric measurements can be found in the "Supporting information" section.

\section{Femtosecond to Nanosecond Resolved Measurements}

All picosecond transients were measured by using commercially available (IBH, UK) picosecond-resolved time correlated single photon counting (TCSPC) setup (instrument response function (IRF) of $80 \mathrm{ps}$ ) using $409 \mathrm{~nm}$ excitation laser source with temperature control setup from Julabo (Model: F32). The temperature dependent femtosecond-resolved fluorescence is measured using a femtosecond upconversion setup (FOG 100, CDP) along with an indigenous temperature controller setup [25]. The sample is excited at $410 \mathrm{~nm}(0.5 \mathrm{~nJ}$ per pulse), using the second harmonic of a mode-locked Ti-sapphire laser with an $80 \mathrm{MHz}$ repetition rate (Tsunami, Spectra Physics), pumped by $10 \mathrm{~W}$ Millennia (Spectra Physics). The fundamental beam is frequency doubled in a nonlinear crystal $\left(1 \mathrm{~mm} \mathrm{BBO}, \theta=25^{\circ}, \phi=90^{\circ}\right)$. The fluorescence emitted from the sample is up-converted in a nonlinear crystal $\left(0.5 \mathrm{~mm} \mathrm{BBO}, \theta=10^{\circ}, \phi=90^{\circ}\right)$ using a gate pulse of the fundamental beam. The upconverted light is dispersed in a double monochromator and detected using photon counting electronics. A cross-correlation function obtained using the Raman scattering from water displayed a full width at half maximum (FWHM) of 165 fs. The details of time resolved measurements and data analysis procedure can be found in the "Supporting information" section.

Molecular Modeling Studies

For the molecular modeling studies, we have followed the procedure as reported earlier for the calculation of caffeine hetero-dimer with a number of DNA-intercalating dyes [2]. We have used commercially available ChemBio3D (from
CambridgeSoft ${ }^{\mathrm{TM}}$ ) ultra software. The force field employed for these calculations is MM2 with default parameters provided with the software. Conjugate gradient methods were used to search for geometry-optimized structures with a convergence criterion of $0.0001 \mathrm{kcal} / \AA$. The minimized energy values of the various complexes as investigated in the present study (caffeine-caffeine, caffeine-DCM, caffeine-C500 and caffeine-TNS) were obtained by first geometry optimizing each component of the complex in vacuum. These geometry-optimized components were then brought together in a face to face orientation and to within van der Waals radii and re-optimized. Relative binding energies were determined by subtracting the sum of the geometry-optimized energies of the isolated components from the total energy obtained for the geometry-optimized complex. In general the lowest energy conformation is that in which the caffeine is oriented directly over the conjugated rings of the various dyes with an average face to face distance of $3.5 \AA$. It must be pointed out that the orientation of the caffeine relative to the dyes in the geometry-optimized complexes is not unique. For example, small displacement $(\sim 1 \AA)$ and rotation of the caffeine by $180^{\circ}$ relative to a dye ring system does not significantly alter the relative binding energy. The relative binding energies derived from molecular mechanics methods can be further deconvoluted into individual components that makeup the total energy. In our present study we like to be limited in the overall stabilization energy of the complexes as shown in Table 1. However, we have recognized that the dominant force in the formation of such complexes appears to be van der Waals interactions resulting in maximal ring overlap between the two molecules of the complexes.

\section{Results and Discussion}

Characterization of Caffeine Dimer in Aqueous Solution

As shown in Table 1 and Scheme 1, our molecular modeling studies reveal a stable stacked dimer of caffeine molecules with stabilization energy of $\sim 10 \mathrm{kcal} / \mathrm{mole}$. Our estimated value of the stabilization energy is close proximity of the reported value of $39.9 \mathrm{~kJ} /$ mole $(\sim 9.5 \mathrm{kcal} /$ mole) from the molecular modeling (using Gaussian package) and X-ray crystallographic studies [26]. As a direct evidence of the formation of caffeine aggregates, we perform temperature and concentration dependent DLS measurements of aqueous caffeine solution (Fig. 1). High concentration of caffeine in aqueous solution $(0.9 \mathrm{M})$ is reached at a high temperature of $80{ }^{\circ} \mathrm{C}$. We observe a hydrodynamic diameter of $\sim 1 \mathrm{~nm}$ with no signature of any larger sized aggregates, and this 
Table 1 Summary of molecular modeling caffeine-dye complexes. Error $\pm 7 \%$

\begin{tabular}{lccc}
\hline Complex & $\begin{array}{c}\text { Total Energy }{ }^{*}(\mathrm{E}) \\
\text { (kcal/mole) }^{-}\end{array}$ & $\begin{array}{l}\text { Complex Energy } \\
\text { (kcal/mole) }\end{array}$ & $\Delta \mathrm{E}^{\ddagger}(\mathrm{kcal} / \mathrm{mole})$ \\
\hline CAF-CAF & 55.56 & 45.53 & -10.03 \\
CAF-DCM & 51.91 & 40.7 & -11.21 \\
CAF-DCM-CAF & 79.69 & 57.48 & -22.21 \\
CAF-C500 & 46.89 & 36.18 & -10.71 \\
CAF-C500-CAF & 74.67 & 52.91 & -21.68 \\
CAF-TNS (Phenyl side) & 28.58 & 20.85 & -7.73 \\
CAF-TNS (Naphthalene side) & 28.58 & 18.41 & -17.32 \\
CAF-TNS-CAF (Both CAF are in Phenyl side) & 56.36 & 39.04 & -17.32 \\
CAF-TNS-CAF (One CAF is in Phenyl side another is in Naphthalene side) & 56.36 & 29.29 & -27.07 \\
CAF-TNS-CAF (Both CAF are in Naphthalene side) & 56.36 & 28.07 & -28.29 \\
\hline
\end{tabular}

$\mathrm{CAF}=$ Caffeine

*Mathematical sum of energy (E) for each molecule in the complex.

\#Total energy calculated for various configurations of the molecular complexes.

$¥$ Difference between mathematical sum of energies of individual molecules and calculated energies of each complex.

feature does not show any significant change with the variation of temperature from $5^{\circ}$ to $80{ }^{\circ} \mathrm{C}$ (Fig. 1). A similar size distribution is observed when the concentration of the solution is increased from $45 \mathrm{mM}$ to $900 \mathrm{mM}$. Since the radius of caffeine molecule is $3.76 \AA$ [27] the observed hydrodynamic diameter of $\sim 1 \mathrm{~nm}$ in caffeine solution does not support the probability of formation of large caffeine aggregates over the studied temperature and concentration range.

To reconfirm the self-association of caffeine, we also carry out FTIR and densimetric measurements, and the results are shown in Fig. 2. Figure 2a shows the FTIR transmittance spectra for caffeine at different concen-

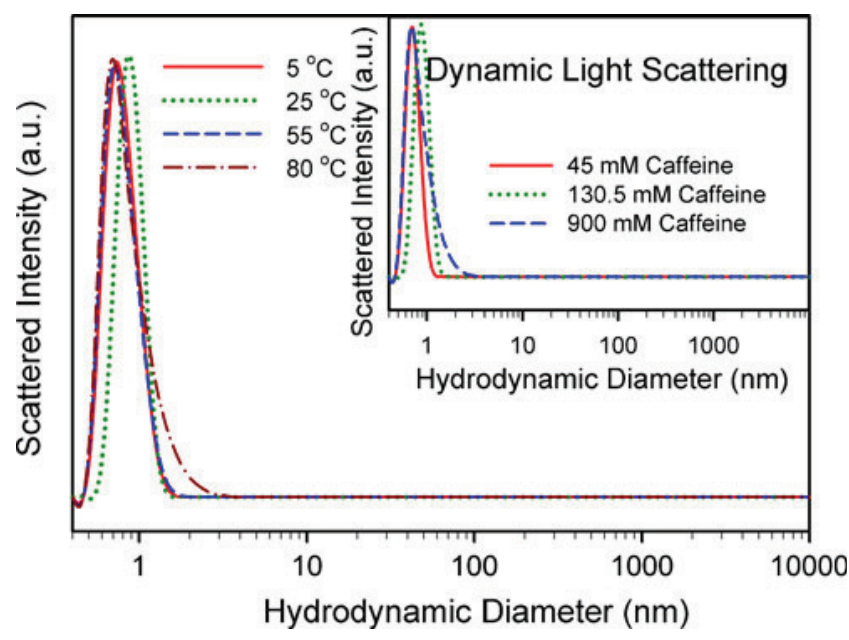

Fig. 1 Hydrodynamic diameter (as obtained from DLS measurements) of $130.5 \mathrm{mM}$ aqueous caffeine solutions at three different temperatures. DLS measurements of caffeine solution with three different concentrations at $25^{\circ} \mathrm{C}$ are shown in the inset trations. The spectrum is in good agreement with previously reported studies $[14,28,29]$. The major information of caffeine stretching is confined in the $1700-1640 \mathrm{~cm}^{-1}$ region in which two major peaks are obtained, one in the $1692-1700 \mathrm{~cm}^{-1}$ region (band 1) due to the stretching of the isolated carbonyl, and the other one in the 1641-1647 $\mathrm{cm}^{-1}$ region (band 2), due to the stretching of the conjugated carbonyl. Less intense bands are produced in the $1570 \mathrm{~cm}^{-1}$ region due to $\mathrm{C}=\mathrm{N}$ and $\mathrm{C}$ $=\mathrm{C}$ stretching vibrations of the purine ring. As can be observed from Fig. 2a, negligible change in the peak position of band 1 and band 2 occurs with increase in the caffeine concentration indicating the presence of no higher order aggregates $[28,29]$. It can also be noted here that in case of stacked dimers of caffeine, full hydration of the carbonyl group is hindered due to steric hindrance, which may in turn cause a wavenumber shift of $\mathrm{C}=\mathrm{O}$ stretching mode by $\sim 20 \mathrm{~cm}^{-1}$. Thus the present result concludes the presence of the dimers with relatively lower hydration of caffeine which corroborates the compressibility studies (see later). Our observation complies with earlier studies [14] involving theoretical Monte Carlo simulation, FTIR and NMR spectroscopies revealing that caffeine molecules associate to form stacked dimers in water that are energetically more favourable than monomers.

In order to understand the nature of hydration in caffeine aggregates, we perform density and sound velocity measurements and the results are depicted in Fig. 2b and Table 2. As observed from Fig. 2b and Table 2, the apparent molar volume $\left(\phi_{\mathrm{v}}\right)$ decreases with increasing concentration of caffeine. However, the concentration vs. $\phi_{\mathrm{v}}$ plot does not produce a good linear fit generally observed for many small 

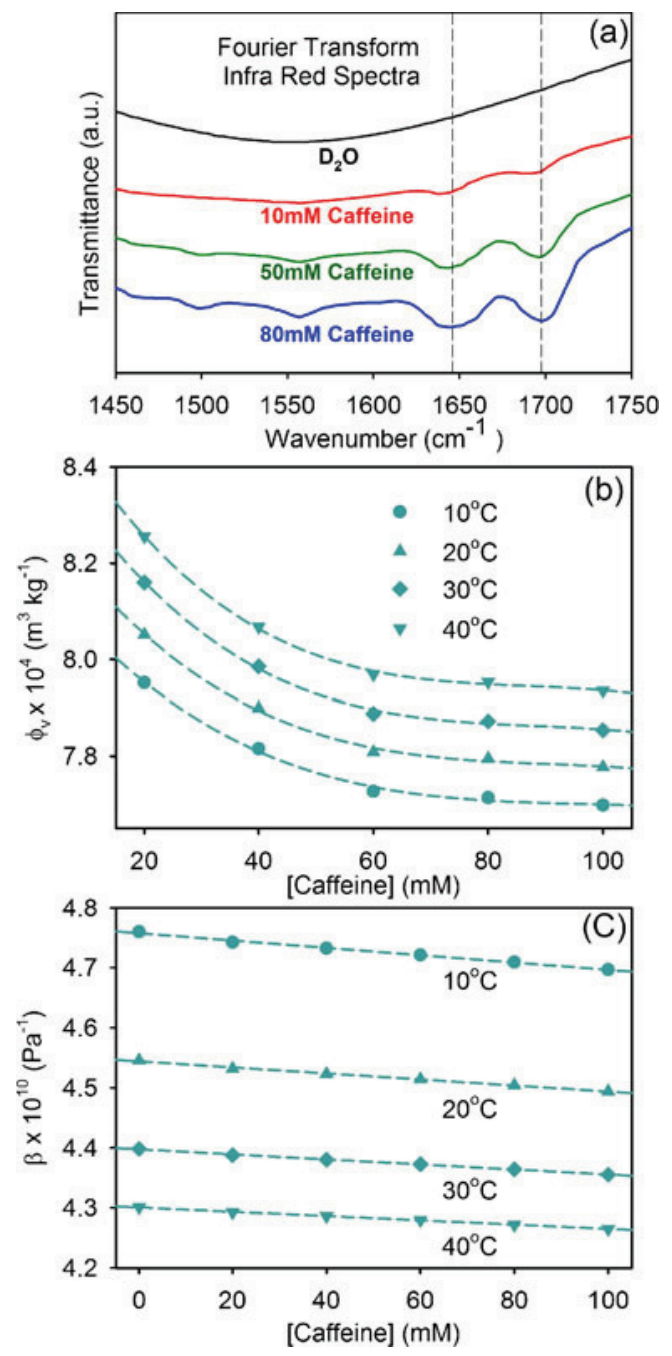

Fig. 2 a FTIR spectra of caffeine solutions at different concentrations $(10 \mathrm{mM}, 50 \mathrm{mM}$ and $80 \mathrm{mM})$. The broken line indicate $\mathrm{C}=\mathrm{O}$ stretching frequencies. b Partial molar volume of caffeine as a function of caffeine concentration in solution at different temperatures. The broken lines are polynomial fits. c Adiabatic compressibility of aqueous caffeine solution as a function of caffeine concentration at different temperatures. The broken lines are linear fits

ionic compounds. We attempt to fit the curves in a polynomials of concentration (c),

$\phi_{v}=\phi_{v}^{0}+\sum_{i=1}^{n} S_{v_{i}} c^{i}$

and found the $\phi_{v}^{0}$ values as $8.192 \times 10^{-4}, 8.326 \times 10^{-4}$, $8.478 \times 10^{-4}$ and $8.602 \times 10^{-4} \mathrm{~m}^{3} \mathrm{~kg}^{-1}$ at $10,20,30$ and $40{ }^{\circ} \mathrm{C}$, respectively, which are relatively large compared to the small solute molecules but are considerably close to the values reported for large organic molecules [30]. The departure from linear behavior of caffeine molecules strongly suggests its association behavior in aqueous solution as has been found from the FTIR and DLS measurements.
The ultrasonic velocity and adiabatic compressibility $(\beta)$ decreases with increasing caffeine concentration (Fig. 2c and Table 2), a trend similar to that observed for electrolyte solutes $[31,32]$ in which increasing electrolyte concentration makes more water molecules to electrorestrict resulting in a decrease in the fraction of bulk water in the solution. This is unusual for a neutral molecule like caffeine to show a negative $d \beta / d c$ slope. However, the slope $d \beta / d c$ is very small for caffeine indicating a low hydration number associated with caffeine, similar to that reported earlier [27]. It is known that $d \beta / d c$ is negative for structured water while it is positive for the non-structured one [33]. A small negative value of $d \beta / d c$ thus indicates that the hydration water molecules are rather weakly attached to the caffeine dimers.

Complexation of Caffeine Dimer with DCM: Dynamics of Solvation

The molecular modeling studies on the caffeine-DCM complexation (Table 1, Scheme 1) confirm that ternary complex of two molecules of caffeine and one DCM molecule $(22.21 \mathrm{kcal} / \mathrm{mole})$ is much stable compared to the hetero dimer of caffeine and DCM (11.21 kcal/mole), which has almost similar stabilization energy of caffeine dimer. DCM, being completely insoluble in water, can be solubilized only within some self organized assemblies in aqueous solution [34]. We monitor the solubility of DCM in caffeine solution as a function of caffeine concentration by measuring the optical density of DCM at the absorption maximum (Fig. 3a). From the plot it is evident that the solubility of DCM increases linearly beyond $40 \mathrm{mM}$, and at $140 \mathrm{mM}$ caffeine concentration $1 \mu \mathrm{M}$ DCM can be solublized in the solution. Therefore it can be concluded that $1.4 \times 10^{5}$ molecules of caffeine are involved to solubilize 1 molecule of DCM. Two different conditions can give rise to such result. Firstly, if caffeine forms a large aggregate with critical concentration of $40 \mathrm{mM}$ and secondly, if there is a hetero-association of caffeine with DCM at high caffeine concentration. The probability of caffeine forming large aggregate with critical concentration of $40 \mathrm{mM}$ can be ruled out from the DLS experimental result where we found no signature of aggregate formation in the solution of $140 \mathrm{mM}$ caffeine with dissolved DCM (data not shown). The relatively high solubility of DCM in caffeine solution compared to its water-insolubility strongly suggests the self-association of caffeine providing a hydrophobic environment wherein DCM can be solublized. Since DCM has been found to be completely insoluble in aqueous solution of sucrose, urea and guanidine hydrochloride even at a high concentration of $6 \mathrm{M}$ each, the result clearly signifies the entrapment of the probe within caffeine 
Table 2 Apparent molar volume $\left(\phi_{\mathrm{v}}\right)$ and adiabatic compressibility $(\beta)$ of caffeine solutions at different temperatures. Error $\pm 7 \%$

\begin{tabular}{|c|c|c|c|c|}
\hline [Caffeine] $\mathrm{mM}$ & Density $\left(\mathrm{g} \mathrm{cm}^{-3}\right)$ & Sound velocity $\left(\mathrm{m} \mathrm{s}^{-1}\right)$ & $\phi_{\mathrm{v}} \times 10^{4}\left(\mathrm{~m}^{3} \mathrm{~kg}^{-1}\right)$ & $\beta \times 10^{10}\left(\mathrm{~Pa}^{-1}\right)$ \\
\hline \multicolumn{5}{|l|}{ Temp. $=10^{\circ} \mathrm{C}$} \\
\hline 0 & 1.000841 & 1448.87 & - & 4.7596 \\
\hline 20 & 1.001634 & 1450.99 & 7.9516 & 4.7420 \\
\hline 40 & 1.002533 & 1451.87 & 7.8152 & 4.7320 \\
\hline 60 & 1.003482 & 1452.88 & 7.7269 & 4.7209 \\
\hline 80 & 1.004383 & 1454.08 & 7.7136 & 4.7089 \\
\hline 100 & 1.005299 & 1455.36 & 7.6979 & 4.6963 \\
\hline \multicolumn{5}{|l|}{ Temp. $=20{ }^{\circ} \mathrm{C}$} \\
\hline 0 & 0.999320 & 1483.72 & - & 4.5456 \\
\hline 20 & 1.000079 & 1485.43 & 8.0513 & 4.5317 \\
\hline 40 & 1.000956 & 1486.20 & 7.8992 & 4.5230 \\
\hline 60 & 1.00188 & 1486.98 & 7.8082 & 4.5141 \\
\hline 80 & 1.002754 & 1487.98 & 7.7949 & 4.5041 \\
\hline 100 & 1.003647 & 1489.04 & 7.7771 & 4.4937 \\
\hline \multicolumn{5}{|l|}{ Temp. $=30^{\circ} \mathrm{C}$} \\
\hline 0 & 0.996749 & 1510.31 & - & 4.3878 \\
\hline 20 & 0.997474 & 1511.56 & 8.1598 & 4.3802 \\
\hline 40 & 0.998334 & 1512.21 & 7.9855 & 4.3726 \\
\hline 60 & 0.999240 & 1512.84 & 7.8878 & 4.3642 \\
\hline 80 & 1.000094 & 1513.64 & 7.8725 & 4.3553 \\
\hline 100 & 1.000966 & 1514.54 & 7.8540 & 4.3878 \\
\hline \multicolumn{5}{|l|}{ Temp. $=40{ }^{\circ} \mathrm{C}$} \\
\hline 0 & 0.993308 & 1529.91 & - & 4.3011 \\
\hline 20 & 0.994007 & 1530.85 & 8.2555 & 4.2928 \\
\hline 40 & 0.994851 & 1531.36 & 8.0676 & 4.2863 \\
\hline 60 & 0.995737 & 1531.87 & 7.9687 & 4.2796 \\
\hline 80 & 0.996571 & 1532.61 & 7.9529 & 4.2719 \\
\hline 100 & 0.997422 & 1533.23 & 7.9346 & 4.2648 \\
\hline
\end{tabular}

dimers rather aqueous solution with perturbed hydrogen bonding networks.

Figure $3 \mathrm{~b}$ shows the relative emission intensity of DCM in aqueous caffeine solution as a function of caffeine concentration and the inset shows the corresponding emission spectra. The Figure shows significant increase in the emission intensity beyond $40 \mathrm{mM}$ caffeine concentration which corroborates the absorption results (Fig. 3a). In aqueous solution of caffeine, the only probable location of hydrophobic DCM is some hydrophobic pocket. Thus the increase in emission intensity is exclusively due to the relocation of DCM molecule in the hydrophobic environment of low order caffeine aggregates. Earlier studies show that the emission maximum of DCM is produced at $636 \mathrm{~nm}$ in micelles [35]. In microemulsion system the DCM emission peak is blue shifted compared to that in micelles and suffers a progressive red shift from $570 \mathrm{~nm}$ to $625 \mathrm{~nm}$ with increasing water content of the microemulsion [36]. The present observation of the peak at $\sim 635 \mathrm{~nm}$ reveals a hydrophobic environment around DCM molecule which is more or less comparable to that in micelles and large microemulsions, which in turn is close to that obtained in highly polar solvents (like methanol, ethyl acetate, acetonitrile) [37, 38].

We now focus on the dynamics of water molecules (solvation) associated with the caffeine dimers. Figure $4 \mathrm{a}$ depicts the picosecond resolved fluorescence transients of DCM in $146 \mathrm{mM}$ caffeine aqueous solution at $25^{\circ} \mathrm{C}$. As observed from the Figure, the fluorescence transients at the blue end $(580 \mathrm{~nm})$, peak $(630 \mathrm{~nm})$ and at the red end (690 nm) do not differ considerably and there is no rise component in the red end, a situation markedly different from the other self-aggregated systems like micelles [35]. The transients can be fitted biexponentially with time components of $\sim 350 \mathrm{ps}$ and $\sim 800 \mathrm{ps}$, resulting in an average lifetime of $\sim 750 \mathrm{ps}$. It has to be noted that the convolution of cis-trans isomerization dynamics of the probe DCM [39], which is evident in the nonpolar solvents could be of potential concern in the solvation time scales. However, later works on the exploration of solvation 
Fig. 3 a Solubility of DCM at different caffeine concentrations as obtained from absorption measurements. The corresponding absorption spectra are shown in the inset. b Relative fluorescence intensity of DCM at its emission maxima in various caffeine concentrations. The inset shows the corresponding fluorescence spectra

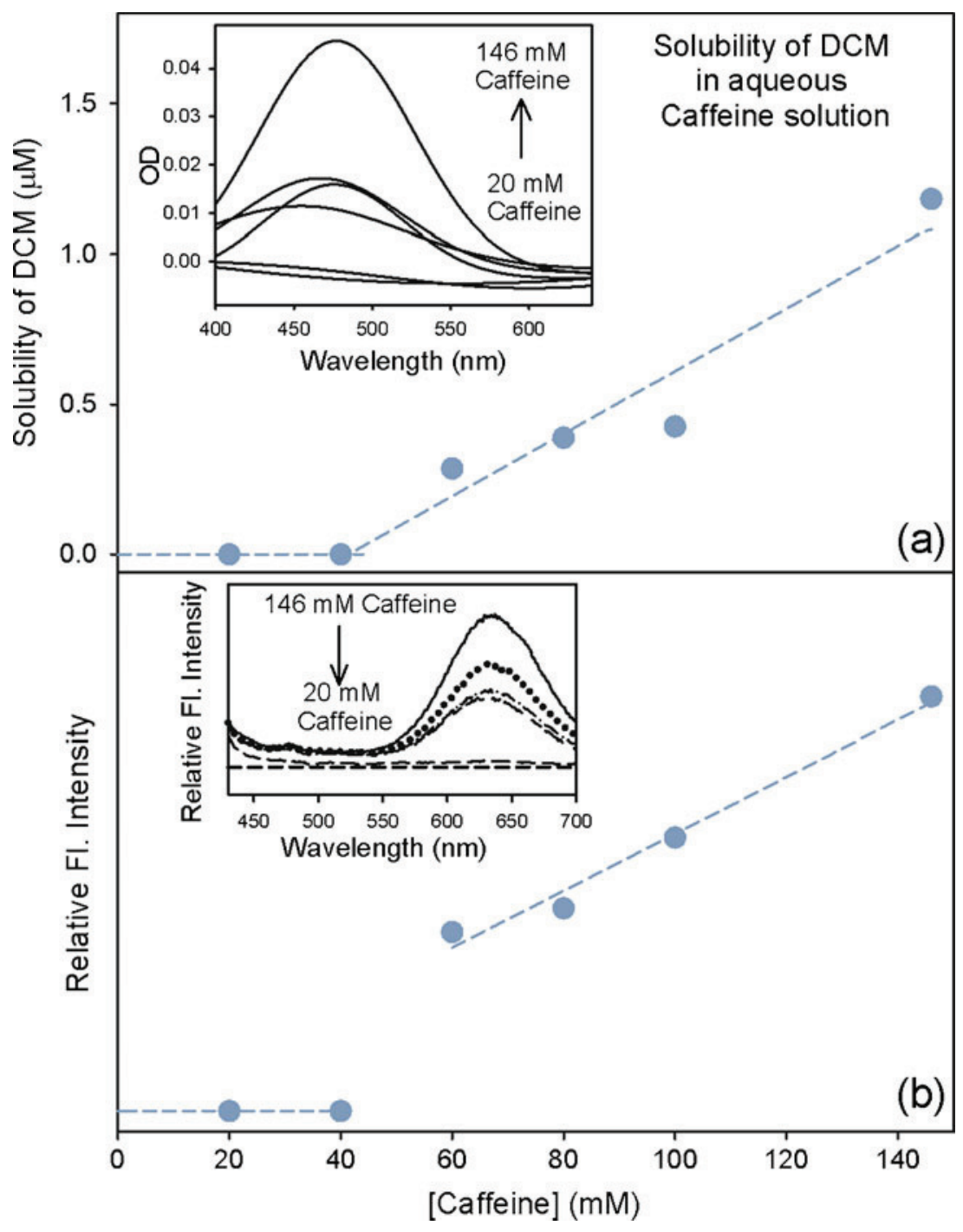

dynamics using the probe DCM have accounted a consequent strong coupling between the locally excited (LE) and charge transfer (CT) states [40] ( 300 fs) in bulk polar solvents rather the isomerization dynamics [41]. The absence of considerable difference in the wavelength dependent fluorescence transients rules out the existence of any slow solvation dynamics, which is typical for aggregates like micelles. This result identifies the hydrated water molecules to be loosely bound to the caffeine dimers as has previously been inferred from compressibility measurements. Identical result is obtained at $80{ }^{\circ} \mathrm{C}$ using a high caffeine concentration of $900 \mathrm{mM}$ (data not shown), concluding that the nature of aggregation and hydration dynamics does not change with temperature as has been observed from the DLS measurements (Fig. 1). In order to study the geometrical restriction on the encapsulated DCM, in other word to investigate the change in the overall hydrodynamic diameter of the caffeine-DCM complex in aqueous solution, we measure the time resolved fluorescence anisotropy of DCM at $25{ }^{\circ} \mathrm{C}$ in $146 \mathrm{mM}$ caffeine solution (Fig. 4a, inset). The transient can be fitted single exponentially with a time constant of $0.31 \mathrm{~ns}$ which is almost similar to that in ethanol $(0.27 \mathrm{~ns})$ but faster than that in micelles [35], thus corroborates with the other experimental results ruling out the possibility of formation of higher order aggregates of caffeine in solution. The rotational relaxation time, $\tau_{\mathrm{r}}$ of the probe is related to the local microviscosity $\eta_{\mathrm{m}}$ experienced by the probe molecule through the Stokes-Einstein-Debye equation (SED) [42, 43],

$\tau_{r}=\eta_{m} V_{h} / k_{B} T$

where $\mathrm{k}_{\mathrm{B}}$ is the Boltzmann constant, $\mathrm{T}$ is the temperature and $V_{\mathrm{h}}$ is the hydrodynamic volume of the probe. Using the $\tau_{\mathrm{r}}$ value in Eq. 2, the hydrodynamic volume of the probe is found to be $1.11 \times 10^{-27} \mathrm{~m}^{3}$ in ethanol and $1.39 \times$ $10^{-27} \mathrm{~m}^{3}$ in caffeine solution. The slightly higher hydrodynamic volume of the probe in the latter system 
(a)
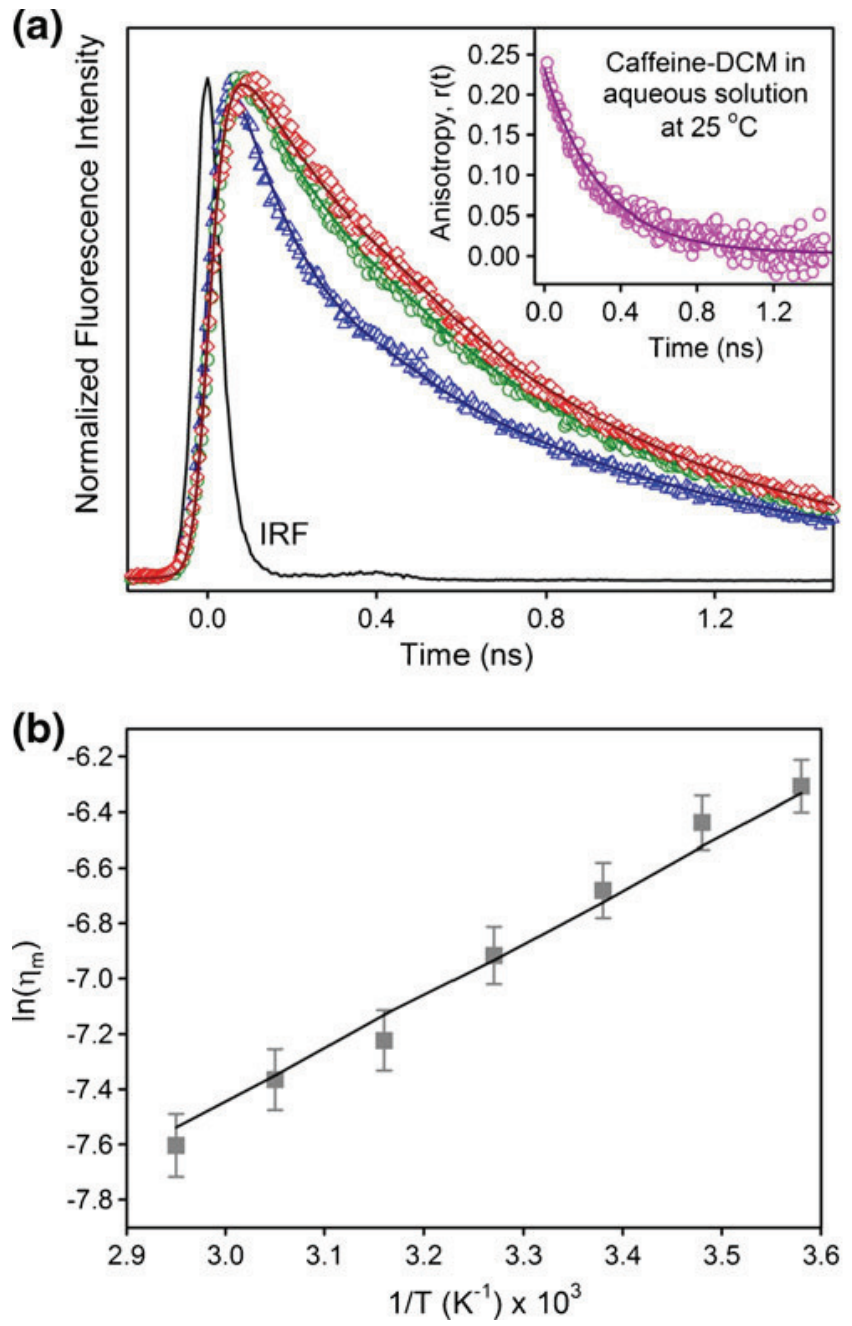

Fig. 4 a Picosecond resolved fluorescence transients of DCM in $146 \mathrm{mM}$ caffeine solution at $25{ }^{\circ} \mathrm{C}$ shown at three characteristic wavelengths of $580 \mathrm{~nm}$ (blue triangles), $630 \mathrm{~nm}$ (green circles) and $690 \mathrm{~nm}$ (red diamonds). The Instrument response function (IRF) is shown for comparison (Excitation at $409 \mathrm{~nm}$ ). The solid lines are exponential fittings. The insets shows time resolved anisotropy, $r(t)$ of DCM in the corresponding solution. The solid line is exponential fit. b Plot of $\ln \left(\eta_{\mathrm{m}}\right)$ against $1 / T$ for caffeine solution. The solid line is a linear fit

assures the interaction of the probe with the caffeine molecules and simultaneously confirms the absence of higher order aggregates of caffeine in aqueous solution. To have a detailed understanding of the microenvironment around DCM at higher temperatures, we measure temperature dependence of the rotational relaxation dynamics. It is observed that $\tau_{\mathrm{r}}$ decreases gradually with increasing temperature indicating that the probe experiences less rotational hindrance at higher temperature (Table 3). The ease of rotation with increasing temperature can be related to an activation energy barrier crossing model and the microviscosity changes with temperature following the relation [44],

$\eta_{m}=\eta_{m}^{0} \exp \left(\frac{-E^{*}}{R T}\right)$
Table 3 Temperature-dependent rotational relaxation time constants $\left(\tau_{\mathrm{r}}\right)$ of DCM in $146 \mathrm{mM}$ aqueous caffeine solution $\left(\mathrm{r}_{0}\right.$ defines anisotropy at time $t=0$ ). Error $\pm 7 \%$

\begin{tabular}{lll}
\hline Temperature $\left({ }^{\circ} \mathrm{C}\right)$ & $\mathrm{r}_{0}$ & $\tau_{\mathrm{r}}(\mathrm{ps})$ \\
\hline 06 & 0.25 & 484 \\
14 & 0.24 & 413 \\
23 & 0.25 & 314 \\
33 & 0.23 & 240 \\
43 & 0.23 & 171 \\
55 & 0.20 & 143 \\
66 & 0.20 & 109 \\
\hline
\end{tabular}

Where $\mathrm{E}^{*}$ is the activation energy for the viscous flow. The plot of $\ln \left(\eta_{\mathrm{m}}\right)$ against 1/T (Fig. 4b) can be linearly fitted within an experimental error of $\pm 1.5 \%$. Aqueous micellar solutions show a relatively large deviation from linear behavior $( \pm 10 \%)$ of temperature dependent microviscosity, which can be explained by the presence of higher order aggregates in the solution in the close proximity of Kraft temperature [44]. The relatively strong linear behavior in the caffeine system confirms the low order selfassociated stacked caffeine dimers. The obtained $\mathrm{E}^{*}$ value of $3.7 \mathrm{kcal} \mathrm{mol}^{-1}$ is comparable to that of the bulk water (3.9 $\mathrm{kcal} \mathrm{mol}^{-1}$ ), but considerably smaller than micellar systems [44].

To ascertain the dynamical states of water molecules associated with the caffeine dimer, we measure the femtosecond resolved fluorescence spectra of DCM in caffeine solution. In order to ensure high signal to noise ratio, we measure the transients at $80{ }^{\circ} \mathrm{C}$ where the caffeine solubility is high enough $(900 \mathrm{mM})$ to provide high signal from the fluorophore. We have also checked the stability of the probe at such elevated temperature in our system and found it to be highly stable. Figure 5a depicts the femtosecond resolved transients in the blue end $(560 \mathrm{~nm})$, peak $(620 \mathrm{~nm})$ and in the red end $(700 \mathrm{~nm})$. As can be observed from the Figure, the transient in the blue end can be fitted triexponentially with three decay components of $0.46 \mathrm{ps}$ (86\%), 22.7 ps (11\%) and 519 ps (3\%). On the other hand, the red end transient exhibits a distinct rise component of $0.94 \mathrm{ps}$ with a decay component of 510 ps. This is a clear indication of the solvation of the dye and we construct the TRES (see Fig. 5b, inset) as per the procedure described in the "Supporting information". From the time dependent Stokes shift we measure the solvent correlation function, $\mathrm{C}(\mathrm{t})$ and plot it against time (Fig. 5b). The curve is well fitted biexponentially with time constants of $0.6 \mathrm{ps}(82 \%)$ and $5.85 \mathrm{ps}(18 \%)$ (Table 4) with a considerable Stokes shift of $800 \mathrm{~cm}^{-1}$. It should be noted here that we miss a considerable 

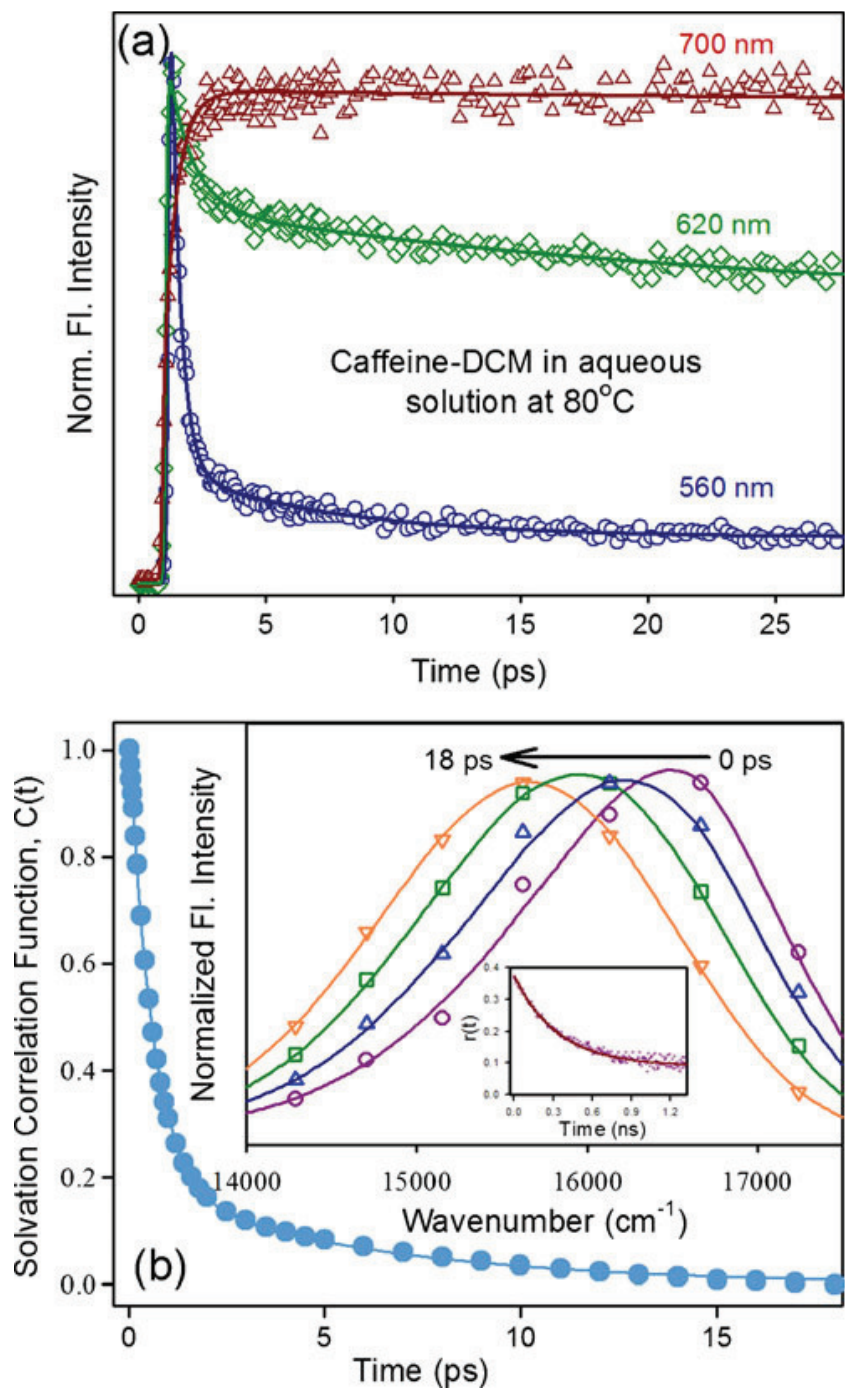

Fig. 5 a Femtosecond-resolved fluorescence transients of DCM in $900 \mathrm{mM}$ caffeine at $80{ }^{\circ} \mathrm{C}$ at three characteristic wavelengths. b Solvation correlation function, $\mathrm{C}(\mathrm{t})$ of the corresponding sample. The solid line is exponential fit. The bigger inset shows the time-resolved emission spectra (TRES) along with the anisotropy (smaller inset) of the same sample

fraction of Stokes shift due to our limited instrumental resolution, and we determined the loss in the dynamic Stokes shift using the procedure developed by Fee and

Table 4 Femtosecond-resolved solvation correlation functions $\mathrm{C}(\mathrm{t})$ for DCM and C500 in aqueous caffeine solution at different temperatures $(\mathrm{T})$ along with the corresponding rotational relaxation time constants $\left(\tau_{\mathrm{r}}\right)$. Error $\pm 7 \%$

\begin{tabular}{lcrrr}
\hline $\begin{array}{l}\text { Aqueous caffeine } \\
\text { solution containing } \\
\text { probe }\end{array}$ & $\mathrm{T}\left({ }^{\circ} \mathrm{C}\right)$ & $\mathrm{C}(\mathrm{t})$ in ps & \multirow{2}{*}{$\tau_{\mathrm{r}}(\mathrm{ps})$} \\
\cline { 3 - 4 } & & \multicolumn{1}{c}{$\tau_{1}$} & \\
\hline $\mathrm{DCM}$ & 80 & $0.6(82 \%)$ & $5.85(18 \%)$ & 330 \\
$\mathrm{C} 500$ & 20 & $0.8(59 \%)$ & $5.42(41 \%)$ & 55 \\
& 80 & $0.44(94 \%)$ & $25(6 \%)$ & 41 \\
\hline
\end{tabular}

Maroncelli [45], where $v(0)$ can be calculated by the following equation,

$v_{e m}^{p}(0)=v_{a b s}^{p}-\left[v_{a b s}^{n p}-v_{e m}^{n p}\right]$

where $v_{a b s}^{p}, v_{a b s}^{n p}$, and $v_{e m}^{n p}$ are the absorption peak in polar solvent, absorption peak in nonpolar solvent, and emission peak in nonpolar solvent, respectively. In the present study, we use dioxane as the nonpolar solvent with absorption and emission maxima of DCM at 455 and $554 \mathrm{~nm}$, respectively. Aqueous solution of caffeine is used as the polar solvent in which DCM produces an absorption peak at $480 \mathrm{~nm}$. We calculate a $34 \%$ loss in the dynamical Stokes shift within the experimental time resolution. The observed $\mathrm{C}(\mathrm{t})$ decay is much slower than that of the pure water [46] (126 fs (20\%) and 880 fs $(35 \%))$ wherein about half of the solvation process occurs in a time scale of experimental time resolution of $30 \mathrm{fs}$. A previous femtosecond-resolved study from our group [25] shows that the solvation time scale of C500 in water is 0.3 and $0.7 \mathrm{ps}$ at room temperature and it reduces to $0.3 \mathrm{ps}$ at $55^{\circ} \mathrm{C}$. In presence of a large ion like guadinium hydrochloride the process becomes slower with time constants of 0.5 and $2.1 \mathrm{ps}$ at room temperature and $0.8 \mathrm{ps}$ at $55^{\circ} \mathrm{C}$. All these time scales are however, faster than those observed for caffeine solutions even at elevated temperature confirming the structured nature of the hydrated water molecules in caffeine solution with respect to an ionic solution. On the other hand these time scales are rather comparable [47] or faster [48] in reverse micelles or micelles [35] confirming our finding that caffeine is aggregated as dimers in aqueous solution and with a rather weakly structured water network around it. The smaller inset inside Fig. 5b inset shows fluorescence anisotropy of DCM at $80{ }^{\circ} \mathrm{C}$ in $900 \mathrm{mM}$ caffeine solution. The transient can be fitted single exponentially with a time constant of 0.33 ns (Table 4) which is close to the one obtained for the probe in $146 \mathrm{mM}$ caffeine at $25^{\circ} \mathrm{C}$. Since DCM is extremely insoluble in water and its solubility in aqueous caffeine solution is only possible due to its confinement inside caffeine dimer, the rotational time constant obtained for the probe actually signifies the time required for rotation of the caffeine in dimeric form. In view of the fact that the anisotropic time scale is much longer compared to the obtained solvation time scales of the same sample it can be concluded that the solvation time scales obtained reflects the dynamics of the bound water around the caffeine dimer and not due to the dynamics of caffeine dimer close to one another at such a high concentration $(900 \mathrm{mM})$.

Complexation of Caffeine Dimer with C500: General Picture of the Dynamics of Solvation for Caffeine Dimer

To confirm the solvation time scales around caffeine dimer at room temperature we repeated the femtosecond-resolved 
experiment using another solvation probe C500 which unlike DCM is sparingly soluble in water. Since solubility of C500 in $100 \mathrm{mM}$ caffeine solution is high enough to provide good signal from the fluorophore we did not use high caffeine concentration. Molecular modeling studies (Table 1 and Scheme 1) on the association of C500 with caffeine also reveal stacked ternary complex of two caffeine molecules and one C500 molecule. We have also checked the stability of the probe at such elevated temperature in our system and found it to be highly stable just like DCM as mentioned before. Since C500 was dissolved in $100 \mathrm{mM}$ caffeine we were able to check the results both at room temperature and at $80{ }^{\circ} \mathrm{C}$. Figure 6a depicts the femtosecond resolved transients at room temperature in the blue end $(450 \mathrm{~nm})$, peak $(500 \mathrm{~nm})$ and in the red end $(600 \mathrm{~nm})$. As can be observed from the Figure, the transient in the blue end can be fitted triexponentially with three decay components of 0.65 ps $(82 \%), 4.35$ ps $(15 \%)$ and $5 \mathrm{~ns}$ (3\%). On the other hand, the red end transient exhibits a
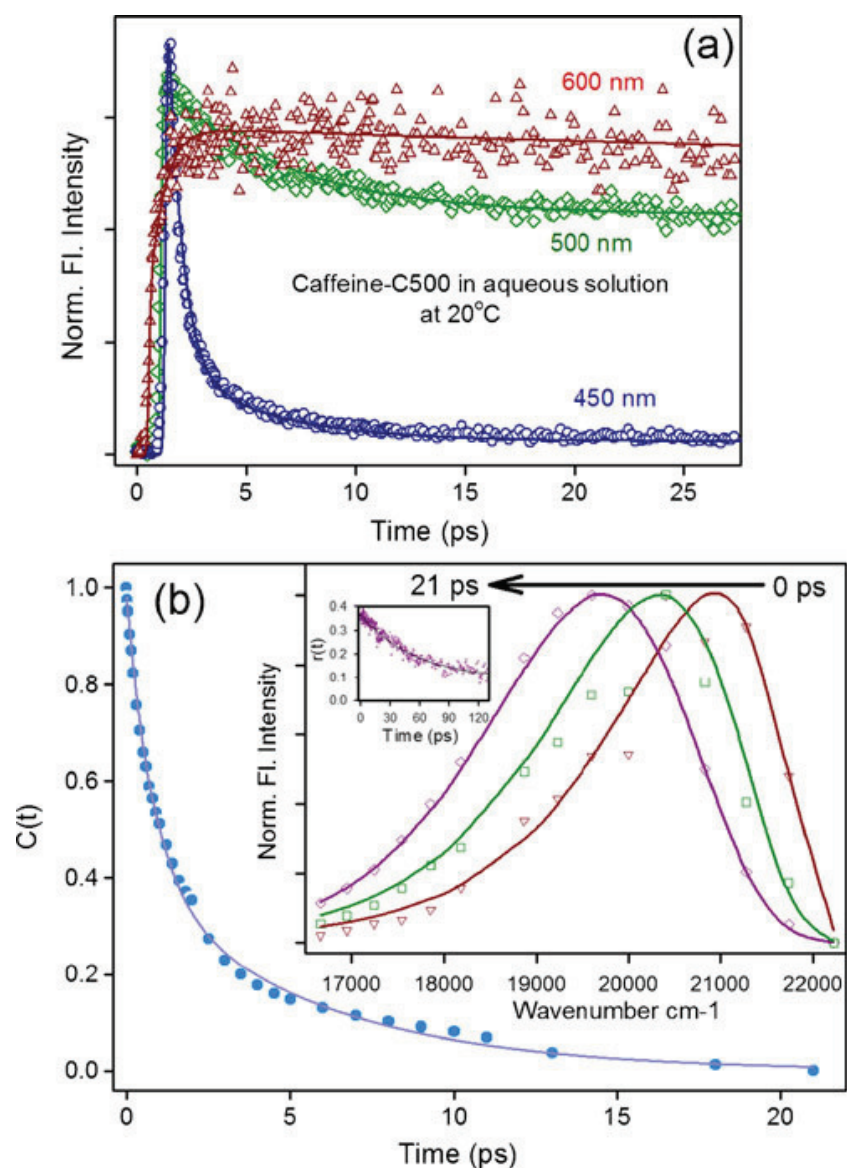

Fig. 6 a Femtosecond resolved fluorescence transient. of C500 in $100 \mathrm{mM}$ caffeine at $20{ }^{\circ} \mathrm{C}$ at three characteristic wavelengths. b Solvation correlation function, $\mathrm{C}(\mathrm{t})$ of the corresponding sample. The solid line is exponential fit. The bigger inset shows the time-resolved emission spectra (TRES) along with the anisotropy (smaller inset) of the same sample distinct rise component of $0.67 \mathrm{ps}$ with decay components of $57 \mathrm{ps}$ and $5 \mathrm{~ns}$. This is a clear indication of the solvation of the dye and we construct the TRES (see Fig. 6b, inset) as per the procedure described in earlier section. From the time dependent Stokes shift we measure the solvent correlation function, $\mathrm{C}(\mathrm{t})$ and plot it against time (Fig. $6 \mathrm{~b}$ ). The curve is well fitted biexponentially with time constants of $0.8 \mathrm{ps}$ $(59 \%)$ and 5.42 ps (41\%) (Table 4). The recovery of similar solvation time scales even after changing the solvation probe reconfirms the dynamical nature of water molecules associated with caffeine dimer. The smaller inset inside Fig. $6 \mathrm{~b}$ inset shows fluorescence anisotropy of $\mathrm{C} 500$ at $20{ }^{\circ} \mathrm{C}$ in $100 \mathrm{mM}$ caffeine solution. The transient can be fitted single exponentially with a time constant of 55 ps (Table 4). The solvation time scales obtained at $80{ }^{\circ} \mathrm{C}$ using $\mathrm{C} 500$ are found to be 0.44 ps (94\%) and 25 ps (6\%) (data not shown). The lack of significant weight of the slower component in the dynamics indicates the release of the probe C500 from the caffeine dimer to the solvent (water). Since the concerned probe C500 is sparingly soluble in water and with temperature its solubility increases, the solvation time scales thus obtained reflects the nature of dynamics of water molecules associated with the probe C500 and not with the caffeine dimer.

TNS in Caffeine Dimer: Excited State Ultrafast Charge Transfer in the Caffeine Dimer

In order to investigate the consequence of the geometrical restriction of guest molecules in the caffeine dimer and the relatively slower dynamics of solvation in the interior of the dimer, we have studied excited state charge transfer reaction of a model probe TNS in the microenvironment. Upon UV excitation TNS undergoes a twisted intramolecular charge transfer (TICT) reaction, which significantly depends on the local solvation and geometrical restriction on the probe [49]. By observing the picosecond to nanosecond dynamics of population and polarizationanalyzed anisotropy for the TNS-caffeine complex, we can also elucidate the nature of local solvation and polarity in the interior of the caffeine dimer. As shown in Table 1 and Scheme 1, our molecular modeling reveals most stable complex of TNS with caffeine molecules to be ternary aggregate of two molecules of caffeine and one molecule of TNS in stacked geometry. It is evident that the stacking of the caffeine molecules in the close proximity of naphthalene ring offers more stabilization compared to other complex geometry.

Interaction of caffeine with TNS was studied by NMR spectroscopy. The aromatic resonances of TNS are shown in the bottommost panel of Fig. 7a. A complete assignment of all resonances was possible using standard 2D correlation experiments. Each resonance is annotated with atom 
Fig. 7 a NMR spectra (aromatic region) of $2 \mathrm{mM}$ TNS in absence and presence of caffeine (caffeine signals are capped by a double bar) at $27^{\circ} \mathrm{C}$ and $\mathrm{pH} 7.2$. The resonances are annotated (see atom numbering shown in panel b). b A cartoon of TNS molecule. The relative sizes of the blue (phenyl ring) and the red (naphthyl ring) circles correspond to the relative change in chemical shift of TNS protons upon addition of $50 \mathrm{mM}$ caffeine (see panel c). c) Change in chemical shift of TNS protons upon caffeine titration. Association constants $\left(\mathrm{K}_{\mathrm{M}}\right)$ obtained by fitting the titration data with Eq. 5 are indicated within parenthesis (in units of $\mathrm{M}^{-1}$ )

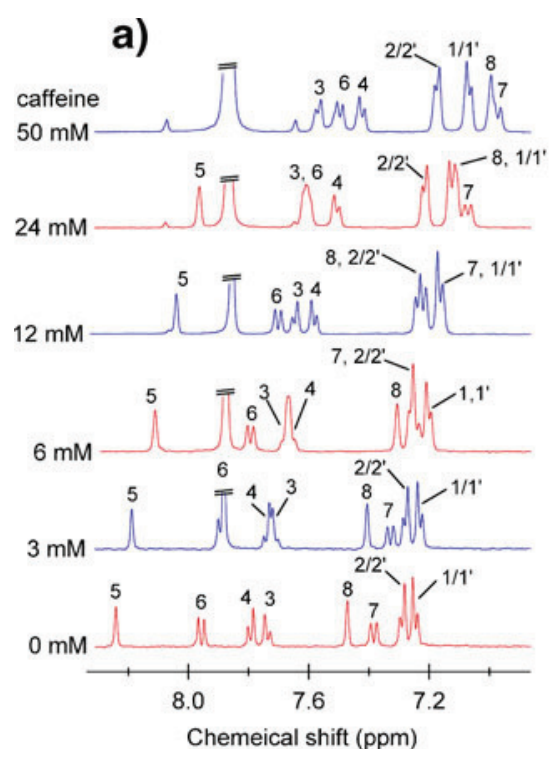

numbers consistent with Fig. 7b. All protons showed upfield shifts upon addition of caffeine as shown in
Fig. $7 \mathrm{a}$ and $\mathrm{c}$. The titration data were fitted with the following equation [50],

$\delta_{\text {obs }}=\delta_{0}+\frac{\Delta \delta^{s a t}}{2 K_{M}[T]_{T}}\left[1+K_{M}\left([C]_{T}+[T]_{T}\right)-\sqrt{\left\{1+K_{M}\left([C]_{T}+[T]_{T}\right)\right\}^{2}-4 K_{M}^{2}[C]_{T}[T]_{T}}\right]$

where $\delta_{\text {obs }}, \delta_{0}$ and $\Delta \delta^{\text {sat }}$ stand respectively for TNS chemical shifts at a given caffeine concentration, in absence of caffeine and change in chemical shift in presence of large excess of caffeine; $\mathrm{K}_{\mathrm{M}},[\mathrm{C}]_{\mathrm{T}}$ and $[\mathrm{T}]_{\mathrm{T}}$ stand for caffeineTNS association constant, total caffeine and TNS concentrations, respectively. The naphthyl ring protons (except for position 3) showed an average $\mathrm{K}_{\mathrm{M}}$ value of $57.4 \pm 5.7 \mathrm{M}^{-1}$ while the phenyl protons and $\mathrm{H} 3$ of the naphthyl ring showed a slightly lower $\mathrm{K}_{\mathrm{M}}$. These two groups of protons are also clearly different from each other when one considers the observed change in the chemical shift at $50 \mathrm{mM}$ caffeine - as depicted in Fig. 7b, the naphthyl protons showed almost double the amount of upfield shift compared to that of the phenyl group (and H3). The observed upfield shifts indicate stacking interaction between TNS and caffeine. The greater effect felt by the naphthyl ring also indicates that caffeine mainly stacks on the naphthyl ring, which corroborates with our molecular modeling studies mentioned before. The odd behavior of the $\mathrm{H} 3$ proton (low net upfield shift), when compared to the behavior of all other naphthyl protons, can be explained if one considers a concomitant change in the twist of the TNS molecule upon caffeine binding. The $\mathrm{H} 3$ proton, closest to the phenyl ring, experiences paramagnetic shielding/deshielding effect of the phenyl ring, the exact nature of which will depend on the relative orientation of the naphthyl/phenyl rings. Upon caffeine binding, while all naphthyl protons feel uniform upfield shift, the $\mathrm{H} 3$ proton will feel an additional effect from the phenyl ring that will depend upon how the relative orientation of the naphthyl/ phenyl ring (twist) changes upon complexation with caffeine. In summary, NMR experiments show the following: i) TNS binds caffeine with a $\mathrm{K}_{\mathrm{M}} \sim 57 \mathrm{M}^{-1}$, ii) the mechanism of binding is stacking between caffeine and the TNS naphthyl ring, iii) stacking is accompanied by a change of the twist angle in the TNS molecule.

Figure 8 a shows the steady state emission spectra of TNS $\left(\lambda_{\text {ex }}=375 \mathrm{~nm}\right)$ in water in absence and presence of caffeine. TNS is almost non-fluorescent in water (quantum yield, $\left.\phi_{\mathrm{f}}=0.001\right)$ with a very short fluorescence life time $\left(\tau_{\mathrm{f}}=60 \mathrm{ps}\right)$ [51]. The extremely low quantum yield $(0.001)$ in water $[46,51]$, indicates that the CT state dynamics are dominated by non-radiative processes, for instance, the fast intersystem crossing as proposed in the literature [52]. As evident from the Figure $8 \mathrm{a}$ the fluorescence intensity of the probe shows a linear enhancement with increase in caffeine concentration. The remarkable sensitivity of TNS is due to the non-radiative twisted intramolecular charge transfer (TICT) process whose rate increases very rapidly with the polarity of the medium $[52,53]$. The dramatic enhancement of the fluorescence intensity of TNS in presence of caffeine is due to the relocation of TNS molecules in the hydrophobic interior of caffeine dimers, which in turn makes the TNS molecules more rigid, retarding the TICT 

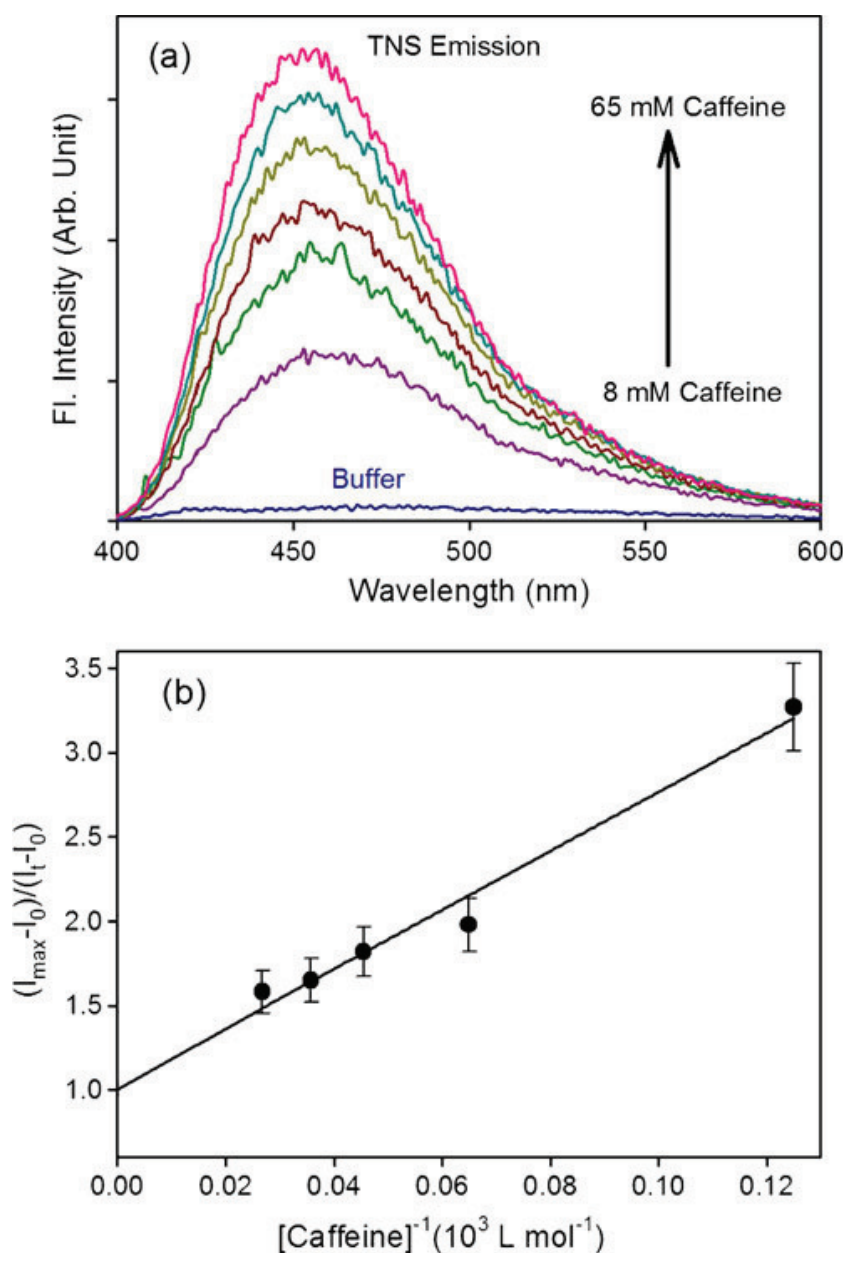

Fig. 8 a Emission spectra of $50 \mu \mathrm{M}$ TNS in absence and presence different caffeine concentrations $\left(\lambda_{\text {ex }}=375 \mathrm{~nm}\right)$. b Almgren plot (see text) of TNS $(50 \mu \mathrm{M})$ for various caffeine concentrations

process in a manner comparable to cyclodextrin (CD) cavity or the micellar aggregates [54-56]. The binding constant $\left(\mathrm{K}_{\mathrm{M}}\right)$ of TNS with caffeine has been calculated from its steady state emission spectroscopy using the relation suggested by Almgren et al. [57],

$\frac{I_{\infty}-I_{0}}{I_{t}-I_{0}}=1+\frac{1}{K_{M}[M]}$

where $I_{\infty}, I_{t}$ and $I_{0}$, denote, respectively, the emission intensities at infinite caffeine concentration, at an intermediate caffeine concentration and in the absence of caffeine, $[\mathrm{M}]$, the caffeine concentration. We plot $\left(\mathrm{I}_{\infty}-\mathrm{I}_{0}\right) /\left(\mathrm{I}_{\mathrm{t}}-\mathrm{I}_{0}\right)$ against 1/[M] which produces good linear fit (Fig. 8b) and $\mathrm{K}_{\mathrm{M}}$ calculated to be $57 \mathrm{M}^{-1}$ which exactly coincides with the one calculated from our NMR experiments. The binding constant of TNS with Triton X-100 (TX) micelles[51] has been reported earlier as $3.5 \times 10^{5} \mathrm{M}^{-1}$ while that with $\beta$ cyclodextrins (CD) $[58,59]$ is $2 \times 10^{3} \mathrm{M}^{-1}$. The observed binding constant of TNS with caffeine is orders of magnitude less compared to those with micelles and cyclodextrins, and consequently model drugs could faster be released from the caffeine dimer compared to the other hosts. The free energy change $\left(\Delta \mathrm{G}^{0}\right)$ associated with the complex formation between TNS and caffeine using the equation can be obtained as,

$\Delta G^{0}=-R T \ln K_{M}$

and the $\Delta G^{0}$ value obtained for the present system is $-2.4 \mathrm{kcal} \mathrm{mol}^{-1}$ which is comparable to the activation energy of viscous flow (see later).

Picosecond resolved fluorescence of TNS in presence of caffeine is presented in Fig. 9. The time resolved emission studies lend further support to the contention that TICT process of TNS gets retarded in presence of caffeine due to the confinement of the probe within the caffeine dimer because of which the lifetime of the fluorophore increases. Figure 9 indicates that while in aqueous solution lifetime of TNS is extremely short (60 ps) [51], in presence of caffeine the fluorescence decay of TNS becomes much slower. The average lifetime of the fluorophore (Table 5) increases from $60 \mathrm{ps}$ in water to $168 \mathrm{ps}$ and $270 \mathrm{ps}$ in presence of 8 and $66 \mathrm{mM}$ caffeine, respectively. The linear enhancement in the lifetime of the fluorophore with increase in the caffeine concentration finds analogy with previous studies [54-56, 59] where it has been reported that the lifetime of TNS increases $\sim 40$ fold in presence of $15 \mathrm{mM} \beta$-CD compared to water. As seen in case of $\mathrm{CD}$ cavity and micellar aggregates $[54,56]$, the twisting motion of the probe gets restricted in presence of caffeine which results in the blockage of the nonradiative TICT process, leading to the enhancement of fluorescence lifetime. To get more insight on the restriction of the probe in caffeine dimer, we measure the time resolved fluorescence anisotropy of TNS in water and in presence of $100 \mathrm{mM}$ caffeine (Fig. 9, inset). In water the transient can be fitted single exponentially with the time constant of 89 ps while it is 318 ps in presence of

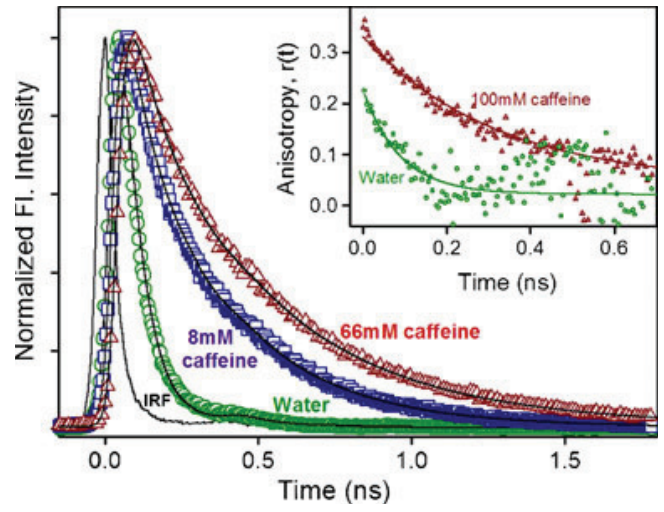

Fig. 9 Picosecond resolved fluorescence transients of TNS in water $(\circ)$ and in presence of $8 \mathrm{mM}(\square)$ and $66 \mathrm{mM}(\Delta)$ caffeine. The inset shows the fluorescence anisotropy of TNS in water ( 0 ) and in presence of $100 \mathrm{mM}(\Delta)$ caffeine 
Table 5 Change in fluorescence lifetime of TNS with increase in caffeine concentration

\begin{tabular}{llllc}
\hline $\begin{array}{l}\text { Caffeine }] \\
\mathrm{mM}\end{array}$ & $\tau_{1}(\mathrm{ps})$ & $\tau_{2}(\mathrm{ps})$ & $\tau_{3}(\mathrm{ps})$ & $\begin{array}{c}\text { Average lifetime } \\
<\tau>(\mathrm{ps})\end{array}$ \\
\hline 0 & $60(100 \%)$ & & & 60 \\
8 & $39(46 \%)$ & $242(48 \%)$ & $567(6 \%)$ & 168 \\
15 & $39(40 \%)$ & $236(46 \%)$ & $519(14 \%)$ & 197 \\
28 & $39(37 \%)$ & $251(47 \%)$ & $567(16 \%)$ & 223 \\
37 & $39(35 \%)$ & $237(43 \%)$ & $549(22 \%)$ & 236 \\
46 & $42(36 \%)$ & $258(45 \%)$ & $594(19 \%)$ & 244 \\
58 & $46(35 \%)$ & $262(43 \%)$ & $608(22 \%)$ & 263 \\
66 & $50(37 \%)$ & $287(43 \%)$ & $640(20 \%)$ & 270 \\
\hline
\end{tabular}

$\tau$ represents the time constant and the figures in the parenthesis represent relative contribution of the component. Error $\pm 7 \%$

$100 \mathrm{mM}$ caffeine. Applying SED (Eq. 2) as mentioned before, the hydrodynamic volume of the probe found to be $0.4 \times 10^{-27} \mathrm{~m}^{3}$ in water and $1.45 \times 10^{-27} \mathrm{~m}^{3}$ in presence of $100 \mathrm{mM}$ caffeine. The increase in the hydrodynamic volume of the probe provides evidence of the heteroassociation of the fluorophore with caffeine dimer [14, 29], which corroborates with the molecular modeling studies represented in Scheme 1 and Table 1 and the NMR results as have been mentioned before.

The temperature dependent fluorescence transient of TNS in presence of $100 \mathrm{mM}$ caffeine is depicted in Fig. 10a and Table 6. The average lifetime $\left(\langle\tau\rangle=\Sigma \mathrm{a}_{\mathrm{i}} \tau_{\mathrm{i}}\right.$ where $\tau_{i}$ represents the lifetime and $a_{i}$ represents the relative contribution of the $i^{\text {th }}$ component) of the fluorophore when associated with caffeine decreases from $355 \mathrm{ps}$ to $192 \mathrm{ps}$ as temperature rises from $6{ }^{\circ} \mathrm{C}$ to $75^{\circ} \mathrm{C}$. Rise in temperature leading to the dissociation of TNS-caffeine complex releases TNS into the water facilitating the nonradiative TICT process which results faster fluorescence decay of the probe as observed. The result is in good agreement with the temperature dependent time resolved fluorescence anisotropy of TNS in $100 \mathrm{mM}$ caffeine (Fig. 10a, inset). The rotational time constant of TNS decreases from 363 ps at $9{ }^{\circ} \mathrm{C}$ to $80 \mathrm{ps}$ at $81{ }^{\circ} \mathrm{C}$ (Table 7). The ease of rotation of TNS with rise in temperature reconfirms release of TNS into water from caffeine bound state due to thermal dissociation of TNS-caffeine complex. The temperature dependence of the average lifetime of the fluorophore can be exploited to obtain the activation energy of the TICT process of the fluorophore through the Arrhenius equation [60]. Figure $10 \mathrm{~b}$ shows the Arrhenius plot for TNS in $100 \mathrm{mM}$ caffeine and activation energy $\left(E_{a c t}\right)$ has been estimated as $1.8 \pm 0.3 \% \mathrm{kcal} \mathrm{mol}^{-1}$, the activation energy thus obtained reflects the energy barrier for the transition of the locally excited (LE) state to the CT
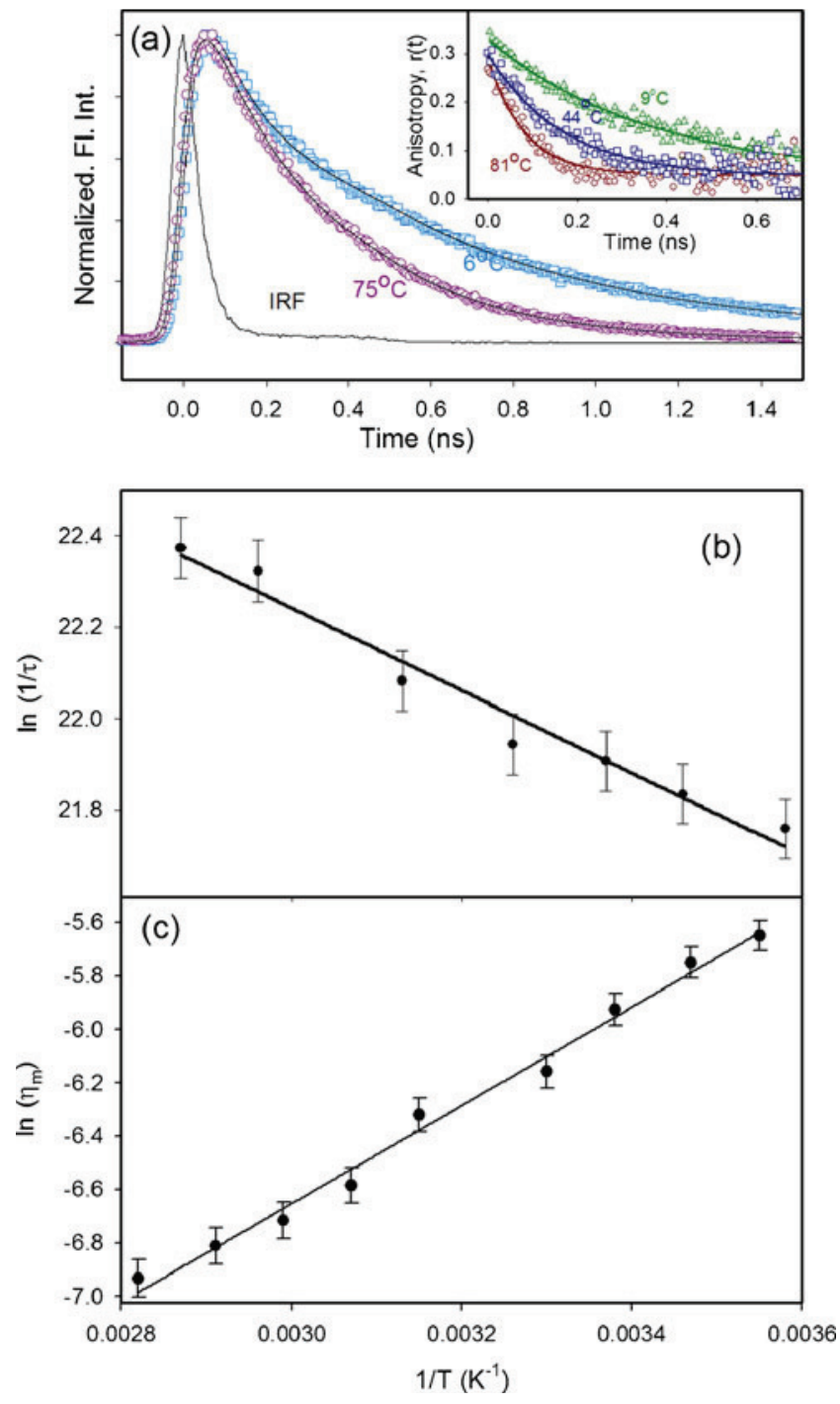

Fig. 10 a Temperature dependent fluorescence transients of TNS-caffeine complex at $6{ }^{\circ} \mathrm{C}(\square)$ and $75^{\circ} \mathrm{C}(\circ)$. The inset shows the anisotropy of TNS in presence of caffeine at $9^{\circ} \mathrm{C}(\Delta), 44^{\circ} \mathrm{C}(\square)$ and $81^{\circ} \mathrm{C}(\circ)$. b The plot of $\ln$ $(1 / \tau)$ against $1 / \mathrm{T}$ for TNS-caffeine solution. The solid line is the corresponding numerical fit of the Arrhenius equation (see text). c The plot of $\ln \eta_{\mathrm{m}}$ against 1/T for TNS-caffeine solution. The solid line is the corresponding numerical fit of Arrhenius type plot (see text)

state of the probe TNS. In contrast to the nearly barrierless twisting motion of the probe in pure water, the energy barrier of such motion of the probe increases upon binding to caffeine as has been observed upon binding to protein [49] due to the lower micropolarity on binding sites. In order to estimate microviscosities we have used the simple SED (Eq. 2). Microviscosity is the friction experienced by a probe molecule at the microscopic scale; it is an important parameter for characterizing the local environment because modest changes in local viscosity lead to variation in physical as well as chemical properties. The microviscosity changes with temperature following the relation mentioned before in Eq. 3. The plot of $\ln \eta_{\mathrm{m}}$ against 1/T (Fig. 10c) can 
Table 6 Change in fluorescence lifetime of TNS in presence of $100 \mathrm{mM}$ caffeine with rise in temperature $(\mathrm{T})$

$\tau$ represents the time constant and the figures in the parenthesis represent relative contribution of the component. Error $\pm 7 \%$

\begin{tabular}{llllc}
\hline $\mathrm{T}\left({ }^{\circ} \mathrm{C}\right)$ & $\tau_{1}(\mathrm{ps})$ & $\tau_{2}(\mathrm{ps})$ & $\tau_{3}(\mathrm{ps})$ & Average lifetime $<\tau>(\mathrm{ps})$ \\
\hline 6 & $1069(13.7 \%)$ & $432(42.2 \%)$ & $60(44.1 \%)$ & 355 \\
16 & $1069(8.7 \%)$ & $432(48.6 \%)$ & $60(42.7 \%)$ & 329 \\
24 & $1069(5.8 \%)$ & $432(50.5 \%)$ & $60(43.7 \%)$ & 306 \\
34 & $1099(4.8 \%)$ & $388(57.1 \%)$ & $54(38.1 \%)$ & 295 \\
46 & $761(7.5 \%)$ & $330(56 \%)$ & $43(36.5 \%)$ & 257 \\
65 & $1294(1.6 \%)$ & $299(57.6 \%)$ & $23(40.8 \%)$ & 192 \\
75 & $1141(1.7 \%)$ & $259(63.9 \%)$ & $22(34.4 \%)$ & 202 \\
\hline
\end{tabular}

be linearly fitted within the experimental error of $\pm 1 \%$. The $\mathrm{E}^{*}$ value is estimated to be $3.7 \mathrm{kcal} \mathrm{mol}^{-1}$ which exactly corroborates with the $E^{*}$ value obtained using DCM (mentioned before) in place of TNS and thus confirms that both DCM and TNS shares similar microenvironment around them in aqueous caffeine solution i.e. both of them are confined within the caffeine dimer (Scheme 1, Table 1). It has to be noted here that the activation energy estimated for the transition of LE state to the CT state of the probe TNS is lower compared to that of the viscous flow which indicates that the CT state of the probe is stabilized by labile water molecules at higher temperature even before the probe dissociates from the caffeine dimer. The activation energy of the viscous flow along with the change in free energy associated with the complexation of TNS with caffeine gives us an idea about the amount of energy that is required to release the probe from the caffeine bound state, which is noteworthy for choosing caffeine as a tool for targeted drug delivery.

\section{Conclusion}

In the present study we have exploited the dimeric nature of caffeine to host some hydrophobic molecules like DCM, C500 and TNS. The results of the molecular modeling

Table 7 Temperature-dependent rotational relaxation time constants $\left(\tau_{\mathrm{r}}\right)$ of TNS in $100 \mathrm{mM}$ aqueous caffeine solution $\left(\mathrm{r}_{0}\right.$ defines anisotropy at time $t=0)$. Error $\pm 7 \%$

\begin{tabular}{llc}
\hline Temperature $\left({ }^{\circ} \mathrm{C}\right)$ & $\mathrm{r}_{0}$ & $\tau_{\mathrm{r}}(\mathrm{ps})$ \\
\hline 9 & 0.35 & 363 \\
15 & 0.35 & 321 \\
23 & 0.30 & 262 \\
30 & 0.35 & 203 \\
44 & 0.30 & 165 \\
53 & 0.30 & 123 \\
62 & 0.26 & 105 \\
71 & 0.29 & 93 \\
81 & 0.27 & 80 \\
\hline
\end{tabular}

calculations provide a mechanistic model of confinement of such molecules within the caffeine dimer that is consistent with the in vitro studies involving NMR experiments. We have explored the hydration dynamics associated with caffeine dimer, which plays a key role in the biomolecular recognition of such xanthine alkaloids. The DLS studies associated with FTIR, sonometric, densimetric and steady state optical experiments clearly reveal the dimeric nature of the caffeine molecules in aqueous solution which is consistent with the previously reported studies. While the sonometric/densimetric studies explore the static picture of hydration around the caffeine dimers, picosecond/femtosecond resolved experiments demonstrate the key time scales associated with the dynamics of hydration. The femtosecond resolved fluorescence study at $80{ }^{\circ} \mathrm{C}$ reveals solvation of the probe with time scales of $0.6 \mathrm{ps}$ and $5.85 \mathrm{ps}$, which are slower than that in bulk water but faster than micelles or reverse micelles confirming the weakly structured nature of the hydrated water molecules. The dynamics of water molecules as revealed by C500 show solvation time scale of 0.3 and $0.7 \mathrm{ps}$ at room temperature and it reduces to $0.3 \mathrm{ps}$ at $55^{\circ} \mathrm{C}$. In presence of a large ion like guadinium hydrochloride the process becomes slower with time constants of 0.5 and 2.1 ps at room temperature and $0.8 \mathrm{ps}$ at $55^{\circ} \mathrm{C}$. All these time scales are however, faster than those observed for caffeine solutions even at elevated temperature confirming the structured nature of the hydrated water molecules in caffeine solution with respect to an ionic solution. Our polarization gated picosecond resolved experiment on the confined DCM and TNS in the caffeine dimer at various temperature explores the activation energy $\left(E^{*}\right)$ for the viscous flow and has been found to be comparable to that of bulk water, which further suggests that very weakly structured water molecules are associated with the caffeine dimers. Very slow water dynamics being a characteristic of strongly bonded water molecules, would have prevented the interaction of such xanthine alkaloids with biomolecules whereas very fast dynamical nature of bound water would not have allowed the formation of caffeine dimer itself. The observed dynamical nature of water molecules associated with caffeine dimer makes it a suitable subject for biomolecular interaction where the 
bound water molecules can be displaced in presence of its receptor molecule facilitating the hydrophobic interaction. Our observations may find the relevance in the exploration of such biomolecular recognition of the most widely consumed caffeine molecules in physiologically relevant environments. Furthermore our exploration of TICT dynamics of TNS in presence of caffeine gives us an idea about the amount of energy required to release such model drugs from the caffeine bound state and this may find significance in further investigation of the use of such xanthine alkaloids as a tool for targeted drug delivery.

Acknowledgements S.B. thanks UGC and P.K.V. thanks CSIR for Research Fellowships. We thank DST for a financial grant (SR/SO/ BB-15/2007). We extend our thanks to Barun Majumder for helping us to carry out the NMR experiments.

\section{References}

1. Selby CP, Sancar A (1990) Molecular mechanisms of DNA repair inhibition by caffeine. Proc Natl Acad Sci 87:3522-3525

2. Larsen RW, Jasuja R, Hetzler RK, Muraoka PT, Andrada VG, Jameson DM (1996) Spectroscopic and molecular modeling studies of caffeine complexes with DNA intercalators. Biophys J 70:443-452

3. Davies DB, Veselkov DA, Djimant LN, Veselkov AN (2001) Heteroassociation of caffeine and aromatic drugs and their competitive binding with a DNA oligomer. Eur Biophys J 30:354-366

4. McKelvey VJ, McKenna PG (1986) Enhanced synergism between caffeine and mitomycin $\mathrm{C}$ in the induction of cytogenetic aberrations in thymidine kinase-deficient Friend murine erythroleukaemia cells. Mutagenesis 1:173-178

5. Mourelatos D, Dozi-Vassiliades J, Kotsis A, Gourtsas C (1988) Enhancement of cytogenetic damage and of antineoplastic effect by caffeine in Ehrlich Ascites tumor cells treated with cyclophosphamide in vivo. Cancer Res 48:1129-1131

6. Andersson HC, Kihlman BA (1987) Effects of G2 treatments with inhibitors of DNA synthesis and repair on chromosome damage induced by X-rays and chemical clastogens in root tips of Vicia faba comparison with corresponding effects in cultured human lymphocytes. Mutat Res 181:173-185

7. Ross WE, Zwelling LA, Kohn KW (1979) Relationship between cytotoxicity and dna strand break-age produced by adriamycin and other intercalating agents. Int J Radiat Oncol Biol Phys 5:1221-1224

8. Iliakis G, Nusse M, Ganapathi R, Egner I, Yen A (1986) Differential reduction by caffeine of adriamycin induced cell killing and cell cycle delays in chinese hamster v79 cells. Int J Radiat Oncul Biol Phys 12:1987-1995

9. Ganapathi R, Grabowski D, Schmidt H, Yen A, Iliakis G (1986) Modulation of adriamycin and N-Trifluoroacetyladriamycin-14valerate induced effects on cell cycle traverse and cytotoxicity in P388 mouse leukemia cells by caffeine and the calmodulin inhibitor trifluoperazine. Cancer Res 46:5553-5557

10. Kimura H, Aoyama T (1989) Decrease in sensitivity to ethidium bromide by caffeine, dimethylsulfoxide or 3-aminobenzamide due to reduced permeability. J Pharmacobio-Dyn 12:589-595

11. Traganos F, Kaminska-Eddy B, Darzynkiewicz Z (1991) Caffeine reverses the cytotoxic and cell kinetic effects of Novantrone (mitoxantrone). Cell Prolif 24:305-319
12. Johansson B, Halldner L, Dunwiddie TV, Masino SA, Poelchen W, Llort LG, Escorihuela RM, Teruel AF, Hallin ZW, Xu XJ, Hårdemark A, Betsholtz C, Herlenius E, Fredholm BB (2001) Hyperalgesia, anxiety, and decreased hypoxic neuroprotection in mice lacking the adenosine $A_{1}$ receptor. Proc Natl Acad Sci 98:9407-9412

13. Vajda S, Jimenez R, Rosenthal SJ, Fidlert V, Fleming GR, Castner EW Jr (1995) Femtosecond to nanosecond solvation dynamics in pure water and inside the y-cyclodextrin cavity. J Chem Soc Faraday Trans 91:867-873

14. Danilov VI, Shestopalova AV (1989) Hydrophobic effect in biological associates: a monte carlo simulation of caffeine molecules stacking. Int J Quantum Chem 35:103-112

15. Falk M, Chew W, Walter JA, Kwiatkowski W, Barclay KD, Klassen GA (1998) Molecular modelling and NMR studies of the caffeine dimer. Can J Chem 76:48-56

16. Kalugin MD, Teplukhin AV (2009) Study of caffeine-DNA interaction in aqueous solution by Parallel Monte Carlo simulation. J Struct Chem 50:841-852

17. Wong ELS, Gooding JJ (2007) The electrochemical monitoring of the perturbation of charge transfer through DNA by Cisplatin. J Am Chem Soc 129:8950-8951

18. Řeha D, Kabelá M, Ryjáek F, Šponer J, Šponer JE, Elstner M, Suhai S, Hobza P (2002) Intercalators. 1. Nature of stacking interactions between intercalators (Ethidium, Daunomycin, Ellipticine, and 4',6-Diaminide-2-phenylindole) and DNA base pairs. $\mathrm{Ab}$ initio quantum chemical, density functional theory, and empirical potential study. J Am Chem Soc 124:3366-3376

19. Maroncelli M, MacInnis J, Fleming GR (1989) Polar solvent dynamics and electron-transfer reactions. Science 243:1674-1681

20. Rips I, Jortner J (1987) Dynamic solvent effects on outer-sphere electron transfer. J Chem Phys 87:2090-2104

21. Hynes JT (1986) Outer-sphere electron-transfer reactions and frequency-dependent friction. J Phys Chem 90:3701-3706

22. Cesaro A, Russo E, Crescenzl V (1976) Thermodynamics of caffeine aqueous solutions. J Phys Chem 80:335-339

23. Bismuto E, Sirangelo I, Adinolfi A, Gaetano Irace G (1990) Dynamic fluorescence of extrinsic fluorophores as a tool for studying protein conformational substates. Biol Metals 3:131-132

24. Sitkowski J, Stefaniak L, Nicol L, Martin ML, Martin GJ, Webb GA (1995) Complete assignments of the 1H, 13C and 15N NMR spectra of caffeine. Spectrochim Acta A Mol Biomol Spectrosc 51:839-841

25. Banerjee D, Verma PK, Pal SK (2009) Temperature-dependent femtosecond-resolved hydration dynamics of water in aqueous guanidinium hydrochloride solution. Photochem Photobiol Sci 8:1441-1447

26. Carlucci L, Gavezzotti A (2005) Molecular recognition and crystal energy landscapes: an X-ray and computational study of caffeine and other methylxanthines. Chem Eur J 11:271-279

27. Jahagirdar DV, Arbad BR, Walvekar AA, Shankarwar AG, Lande MK (2000) Studies in partial molar volumes, partial molar compressibilities and viscosity B-coefficients of caffeine in water at four temperatures. J Mol Liq 85:361-373

28. Maevsky AA, Sukhorukov BI (1980) IR study of base stacking interactions. Nucl Acids Res 8:3029-3042

29. Falk M, Gil M, Iza N (1990) Self-association of caffeine in aqueous solution: an FT-IR study. Can J Chem 68:1293-1299

30. Millero FJ, Surdo AL, Shin C (1978) The apparent molal volumes and adiabatic compressibilities of aqueous amino acids at 25 . degree.C. J Phys Chem 82:784-792

31. Benz R (1961) Some thermodynamic properties of the system $\mathrm{PuCl}_{3}-\mathrm{KCl}$ from electromotive force data. J Phys Chem 65:81-84

32. Bockris JOM, Saluja PPS (1972) Ionic solvation numbers from compressibilities and ionic vibration potentials measurements. J Phys Chem 76:2140-2151 
33. Hirata F, Arakawa K (1972) Ultrasonic study of solute-solvent interaction in aqueous solutions of Tetraalkylammonium salts. Bull Chem Soc Jpn 45:2715-2719

34. Pal SK, Sukul D, Mandal D, Sen S, Bhattacharyya K (2000) Solvation dynamics of DCM in micelles. Chem Phys Lett 327:91-96

35. Sarkar R, Shaw AK, Ghosh M, Pal SK (2006) Ultrafast photoinduced deligation and ligation dynamics: DCM in micelle and micelle-enzyme complex. J Photochem Photobiol B 83:213222

36. Pal SK, Mandal D, Sukul D, Bhattacharyya K (1999) Solvation dynamics of 4-(dicyanomethylene)-2-methyl-6-(p-dimethylaminostyryl)-4H-pyran (DCM) in a microemulsion. Chem Phys Lett 312:178-184

37. Meyer M, Mialocq JC (1987) Ground state and singlet excited state of laser dye DCM: Dipole moments and solvent induced spectral shift. Opt Commun 64:264-268

38. Meuler PVD, Zhang H, Jonkman AM, Glasbeek M (1996) Subpicosecond solvation relaxation of 4-(Dicyanomethylene)-2methyl-6-(p-(dimethylamino)styryl)-4H-pyran in polar liquids. J Phys Chem 100:5367-5373

39. Drake JM, Lesiecki ML, Camaioni DM (1985) Photophysics and Cis_Trans Isomerization of DCM. Chem Phys Lett 113:530-534

40. Zhang H, Jonkman AM, Pvd M, Glasbeek M (1994) Femtosecond studies of charge separation in photo-excited DCM in liquid solution. Chem Phys Lett 224:551-556

41. Easter DC, Baronavski AP (1993) Ultrafast relaxation in the fluorescent state of the laser dye DCM. Chem Phys Lett 201:153-158

42. Philips LA, Webb SP, Clark JH (1985) High-pressure studies of rotational reorientation dynamics: the role of dielectric friction. $\mathrm{J}$ Chem Phys 83:5810-5821

43. Kalman B, Clarke N, Johansson LBA (1989) Dynamics of a new fluorescent probe, 2,5,8,11-tetra-tert-butylperylene in solution, cubic lyotropic liquid crystals, and model membranes. J Phys Chem 93:4608-4615

44. Zana R (1999) Microviscosity of aqueous surfactant micelles: effect of various parameters. J Phys Chem B 103:9117-9125

45. Fee RS, Maroncelli M (1994) Estimating the time-zero spectrum in time-resolved emmsion measurements of solvation dynamics. Chem Phys 183:235-247

46. Jimenez R, Fleming GR, Kumar PV, Maroncelli M (1994) Femtosecond solvation dynamics of water. Nature 369:471-473
47. Riter RE, Willard DW, Levinger NE (1998) Water immobilization at surfactant interfaces in reverse micelles. J Phys Chem B 102:2705-2714

48. Corbeil EM, Levinger NE (2003) Dynamics of polar solvation in quaternary microemulsions. Langmuir 19:7264-7270

49. Zhong D, Pal SK, Zewail AH (2001) Femtosecond studies of protein -DNA binding and dynamics: Histone I. Chem Phys Chem 2:219-227

50. Hirose K (2001) A practical guide for the determination of binding constants. J Incl Phenom Macrocycl Chem 39:193-209

51. Datta A, Mandal D, Pal SK, Das S, Bhattacharyya K (1998) Interaction of triton X-100 with cyclodextrins. A fluorescence study. J Chem Soc Faraday Trans 94:3471-3475

52. Chang TL, Cheung HC (1990) A model for molecules with twisted intramolecular charge transfer characteristics: solvent polarity effect on the nonradiative rates of dyes in a series of water-ethanol mixed solvents. Chem Phys Lett 173:343-348

53. Bhattacharyya K, Chowdhury M (1993) Environmental and magnetic field effects on exciplex and twisted charge transfer emission. Chem Rev 93:507-535

54. Sarkar N, Das K, Nath D, Bhattacharyya K (1992) Interaction of urea with fluorophores bound to cyclodextrins. Fluorescence of ptoluidino naphthalene sulphonate. Chem Phys Lett 196:491-496

55. Nakamura A, Saitoh K, Toda F (1991) Fluctuation in structure of inclusion complexes of cyclodextrins with fluorescent probes. Chem Phys Lett 187:110-115

56. Sarkar N, Das K, Nath D, Bhattacharyya K (1994) Salt effect on the hydrophobic binding of p-toluidino naphthalene sulphonate with cyclodextrins. Chem Phys Lett 218:492-498

57. Almgren M, Grieser F, Thomas JK (1979) Dynamic and static aspects of solubilization of neutral arenes in ionic micellar solutions. J Am Chem Soc 101:279-291

58. Jobe DJ, Verrall RE, Palepu R, Reinsborough VC (1988) Fluorescence and conductometric studies of potassium 2-(pToluidinyl)naphthalene-6-sulfonate/Cyclodextrin/Surfactant systems. J Phys Chem 92:3582-3586

59. Catena GC, Bright FV (1989) Thermodynamic study on the effects of P-cyclodextrin inclusion with anilinonaphthalenesulfonates. Anal Chem 61:905-909

60. Sen P, Mukherjee S, Halder A, Bhattacharyya K (2004) Temperature dependence of solvation dynamics in a micelle. 4-Aminophthalimide in Triton X-100. Chem Phys Lett 385:357-361 